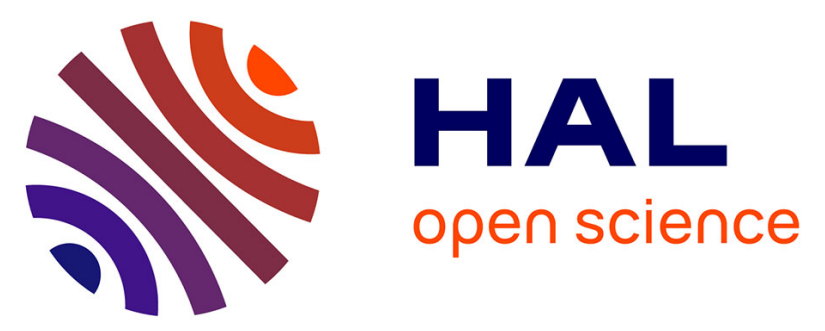

\title{
Enhancement of Pd Catalytic Activity toward Ethanol Electrooxidation by Atomic Layer Deposition of SnO2 onto TiO2 Nanotubes
}

\author{
Maïssa Barr, Loïc Assaud, Nicolas Brazeau, Margrit Hanbücken, Spyridon \\ Ntais, Lionel Santinacci, Elena Baranova
}

\section{To cite this version:}

Maïssa Barr, Loïc Assaud, Nicolas Brazeau, Margrit Hanbücken, Spyridon Ntais, et al.. Enhancement of Pd Catalytic Activity toward Ethanol Electrooxidation by Atomic Layer Deposition of SnO2 onto TiO2 Nanotubes. Journal of Physical Chemistry C, 2017, 121 (33), pp.17727 - 17736. 10.1021/acs.jpcc.7b05799 . hal-01720430

\section{HAL Id: hal-01720430 \\ https://hal.science/hal-01720430}

Submitted on 9 Mar 2021

HAL is a multi-disciplinary open access archive for the deposit and dissemination of scientific research documents, whether they are published or not. The documents may come from teaching and research institutions in France or abroad, or from public or private research centers.
L'archive ouverte pluridisciplinaire HAL, est destinée au dépôt et à la diffusion de documents scientifiques de niveau recherche, publiés ou non, émanant des établissements d'enseignement et de recherche français ou étrangers, des laboratoires publics ou privés. 


\title{
Enhancement of Pd Catalytic Activity Toward Ethanol Electrooxidation By Atomic Layer Deposition of $\mathrm{SnO}_{2}$ onto $\mathrm{TiO}_{2}$ Nanotubes
}

\author{
Maïssa K. S. Barr, ${ }^{\dagger}$ Loïc Assaud, ${ }^{\dagger,}$ Nicolas Brazeau, ${ }^{\#}$ Margrit Hanbücken, ${ }^{\dagger}$ Spyridon Ntais, ${ }^{\#}$ \\ Lionel Santinacci, ${ }^{\dagger}, *$ and Elena A. Baranova ${ }^{\#, *}$ \\ ${ }^{\dagger}$ Aix Marseille Univ, CNRS, CINaM, Marseille, France \\ Institut de Chimie Moléculaire et des Matériaux d'Orsay, Université Paris-Sud/Université \\ Paris-Saclay, CNRS, Rue du Doyen Georges Poitou, F-91405 Orsay, France \\ ${ }^{\#}$ Department of Chemical and Biological Engineering, Centre for Catalysis Research and \\ Innovation, University of Ottawa, 161 Louis-Pasteur St., Ottawa, ON, K1N 6N5, Canada
}

\begin{abstract}
Palladium nanoparticles and $\mathrm{SnO}_{2}$ layers have been grown by two successive steps of atomic layer deposition onto $\mathrm{TiO}_{2}$ nanotubes (TNTs). The three-dimensional nanostructured catalytic systems have been studied for ethanol electrooxidation in alkaline media. Characterization by scanning and transmission electron microscopies, $\mathrm{x}$-ray photoelectron spectroscopy, and x-ray diffraction indicates the high conformity, the high purity, and the perfect stoichiometry of Pd and $\mathrm{SnO}_{2}$ deposits onto the TNTs. The electrochemical investigations performed by cyclic voltammetry and chronoamperometry have revealed the beneficial effect of the annealing of the support toward ethanol electrooxidation reaction. The comparison of the catalytic activity with literature shows that such $\mathrm{SnO}_{2}$ based substrates exhibits highly promising performances.
\end{abstract}




\section{INTRODUCTION}

Direct alcohol fuel cells (DAFCs) have received a great deal of attention for energy generation and storage in portable electronic devices and vehicles. Among the different possible alcohols, ethanol is a promising liquid fuel because it has no toxicity, a high energy density and it can be easily produced from the fermentation of biomass.$^{1-3}$ However, the ethanol oxidation kinetics on Pt-based catalysts in acidic media is slow, incomplete and mostly leads to the production of acetic acid and acetaldehyde. The recent development of anion exchange solid electrolytes advanced the development of alkaline DAFCs where the oxidation kinetics is faster and allows using cheaper electrocatalysts than Pt. Pt-free catalysts or Pt alloying with co-catalysts can be used for ethanol oxidation reaction (EOR) in alkaline media. ${ }^{4}$ Within this context, palladium has emerged as an attractive candidate for DAFCs. Pd is more abundant and less expensive, however the EOR is not complete in alkaline media leading to acetate and acetaldehyde formation in addition to small amounts of $\mathrm{CO}_{2}$. It is therefore necessary to improve the catalyst to efficiently break the $\mathrm{C}-\mathrm{C}$ bond at low overpotentials. In order to improve the performances of Pd toward ethanol electrooxidation, bimetallic $\mathrm{Pd} / \mathrm{M}(\mathrm{M}=\mathrm{Ru}, \mathrm{Au}, \mathrm{Ir}, \mathrm{Sn}, \mathrm{Ni})$ catalysts have been intensively studied in alkaline media. ${ }^{5-}$ ${ }^{8}$ Another possibility to enhance the performances of Pd based catalyst is the use of a catalyst support with a high surface area and a better stability than conventional carbon black. ${ }^{3}$ The catalyst substrate should promote the formation of well-dispersed and stable Pd particles. The support, in addition to its structural role, can have an electronic effect on the catalyst phase and influence the catalytic activity of metallic particles via metal-support interaction (MSI). ${ }^{9-11}$ This in turn will affect the adsorption strength of ethanol and reaction intermediates resulting in improved catalyst activity and in some cases its selectivity. Numerous nanostructured substrates such as carbon microspheres, hollow carbon spheres, nanowires and carbon nanotubes (CNTs) have been investigated to enhance the catalytic efficiency of Pd and to reduce the costs. ${ }^{12-13}$ Nevertheless, carbon-based materials are not stable and corrode under reaction conditions. $\mathrm{TiO}_{2}$ is well known for its high stability and its strong MSI with Pt group metals. ${ }^{9}$ It is thus an interesting support for Pd particles. ${ }^{14}$ Among the numerous types of titanium dioxide nanostructures, the nanotubes are interesting because the exhibit a high specific area and a well-defined geometry. $\mathrm{TiO}_{2}$ nanotubes (TNTs) can be obtained by different methods such hydrothermal reaction, deposition in templates, molecular assembly templating, electrospinning and anodic oxidation. ${ }^{15}$ The later method is straightforward and offers a large control of the tube morphology. In anodic TNTs, the charge transport and collection are 
facilitated by the nanotubes self-alignment, because they are connected by the Ti substrate. In a previous work, ${ }^{16}$ it has been shown that anodic TNT arrays can be suitable supports for Pd nanoparticles grown by atomic layer deposition (ALD) and that the annealing of titania improves the electrocatalytic activity of the catalysts. Although a high and stable electroactivity has been measured on such Pd/TNT systems further improvements are proposed in the present work through the addition of a $\mathrm{SnO}_{2}$ interlayer between TNTs and Pd nanoparticles.

$\mathrm{SnO}_{2}$ has been widely studied for application in sensors, batteries, photovoltaic cell, optoelectronic device and catalytic application. ${ }^{17}$ There are a number of studies that show a promotional effect of $\mathrm{SnO}_{2}$ support on alcohol electrooxidation. ${ }^{18-21}$ A chemical modification of TNT surface by $\mathrm{SnO}_{2}$ deposition is therefore suitable to enhance the Pd properties toward ethanol electrooxidation. Several techniques can be used to functionalize TNTs with $\mathrm{SnO}_{2}$. The $\mathrm{SnO}_{2}$ has been deposited onto anodic TNTs by solvothermal method, ${ }^{22}$ by electrodeposition ${ }^{23}$ or by ultrasonic deposition. ${ }^{24}$ However, ALD remains a method of choice to grown conformal, particles ${ }^{25}$ or continuous ${ }^{26-27}$ oxide layers as well as sulphide ${ }^{28-29}$ films and specially $\mathrm{SnO}_{2}$ onto such nanostructures. ${ }^{30-31}$ To avoid any film contamination, a process with non-halogenated precursor has been used. ${ }^{30,32}$ In recent years, many groups have reported the interest of using ALD to grow metallic nanoparticles onto nanostructured substrate. ${ }^{33-36}$ The amount and the composition of the catalyst are fully controlled, the nanoparticles exhibit the same or better performances than particles grown by other methods..$^{16,37-39}$

The aim of the present study is to compare the electrochemical response of Pd catalysts supported by two different nanostructured materials: bare TNTs and $\mathrm{SnO}_{2}$ coated TNTs. Since the $\mathrm{SnO}_{2}$ deposition proceeds with a negligible variation of the geometry, the influence of the chemical nature of the substrate is solely expected. As schematically presented on Fig. 1, the $\mathrm{SnO}_{2}$ layer and Pd nanoparticles have been successively deposited by ALD onto anodic TNTs ( $\left.\mathrm{Pd} / \mathrm{SnO}_{2} / \mathrm{TNTs}\right)$. The morphology, the chemical composition and the crystalline structure of the $\mathrm{SnO}_{2}$ layer and the Pd catalysts have been investigated by scanning and transmission electron microscopies (SEM and TEM, respectively), x-ray photoelectron spectroscopy (XPS) and x-ray diffraction (XRD). The electroactivity of the $\mathrm{Pd} / \mathrm{SnO}_{2} / \mathrm{TNT}$ s systems toward ethanol electrooxidation has been measured by cyclic voltammetry (CV) and chronoamperometry (CA) as a function of the ALD parameters and depending on the crystalline structure of the $\mathrm{SnO}_{2} /$ TNTs support. 


\section{EXPERIMENTAL}

\section{Preparation of $\mathrm{TiO}_{2}$ nanotubes}

The $\mathrm{TiO}_{2}$ nanotubes have been grown by anodization of Ti foils (Advent, 95.6\% purity) in an aqueous fluoride containing acidic electrolyte $\left(1 \mathrm{M} \mathrm{H}_{3} \mathrm{PO}_{4}+1 \mathrm{M} \mathrm{NaOH}+0.5 \% \mathrm{HF}\right)$ as described in a previous publication. ${ }^{40}$ The electrochemical oxidation was performed under a constant applied potential $(U)$ of $20 \mathrm{~V}$ at room temperature using a high-voltage Modulab potentiostat (Solartron Analytical).

Atomic layer deposition of $\mathrm{SnO}_{2}$

The $\mathrm{SnO}_{2}$ layer was grown by atomic layer deposition in a Fiji 200 reactor from Ultratech/Cambridge Nanotech. The deposit was achieved at $T=200^{\circ} \mathrm{C}$ with tetrakis(dimethylamino)tin (TDMASn, 99.99\%, from Strem chemicals) and hydrogen peroxide (30\% from SigmaAldrich). In order to achieve a high growth per cycle (GPC) $\mathrm{H}_{2} \mathrm{O}_{2}$ has been chosen as oxygen source (Caution: when performing the ALD process, the $\mathrm{H}_{2} \mathrm{O}_{2}$ concentration in the canister can increase due to a distillation phenomenon. The solution can become potentially explosive. A fresh solution should be used for each run). The canister containing the TDMASn was held at $T=80^{\circ} \mathrm{C}$. The socalled exposure mode was used to facilitate the deposition onto the whole TNTs. It consisted of isolating the reactor from the pumping system during each precursor pulse. The ALD process was therefore defined as the successive pulse, exposure and purge steps for both precursors. The sequence durations were 1:10:10 s and 1:10:10 s for TDMASn and $\mathrm{H}_{2} \mathrm{O}_{2}$, respectively. The ALD of $\mathrm{SnO}_{2}$ was performed onto both TNTs and flat $\mathrm{Si}$ (100) substrates to facilitate some characterizations. The amount of deposited stannic oxide was controlled by the number of ALD cycles $\left(N_{\mathrm{SnO}_{2}}\right)$. Modification of the crystalline structure of $\mathrm{SnO}_{2} / \mathrm{TNT}$ s was achieved by an annealing at $450^{\circ} \mathrm{C}$ for $2 \mathrm{~h}$ in air.

\section{Atomic layer deposition of $P d$}

The deposition of the catalyst has been described previously. ${ }^{41}$ It was carry out in the same reactor with palladium(II)hexafluoroacetylacetonate $\left(\operatorname{Pd}(\mathrm{hfac})_{2}, 98 \%\right.$, from Strem Chemicals) and formalin (37\% formaldehyde in water with $10-15 \%$ of methanol from Sigma-Aldrich). The Pd canister was maintained at $90^{\circ} \mathrm{C}$, while the temperature of the reaction chamber was set to $200^{\circ} \mathrm{C}$. 
The pulse, exposure, and purge durations were 1:30:30 s and 3:30:30 s for $\operatorname{Pd}(\mathrm{hfac})_{2}$ and formalin, respectively. The number of ALD cycles $\left(N_{\mathrm{Pd}}\right)$ was varied to adjust the catalyst load.

\section{Characterization Methods}

The thickness of the $\mathrm{SnO}_{2}$ deposit was measured by spectroscopic ellipsometry using a M2000V from J. A. Woollam Inc. The morphology of $\mathrm{SnO}_{2} / \mathrm{TNTs}$ as well as the $\mathrm{Pd} / \mathrm{SnO}_{2} / \mathrm{TNT}$ were characterized by SEM (JSM 6320F, JEOL) and TEM (JEM 3010, JEOL). The crystal structure of the $\mathrm{SnO}_{2}$ layers and the $\mathrm{TiO}_{2}$ substrates were analysed by XRD using a Rigaku RU-200 rotating anode $x$-ray generator (operating power 40 kV/30 mA) equipped with a Xenocs Fox3D Cu 12_INF mirror and a Mar345 image plate detector from Rayonix. Selected-area electron diffraction (SAED) was also performed in the TEM to locally study the crystal structure of the $\mathrm{Pd} / \mathrm{SnO}_{2} / \mathrm{TNT}$ s systems . The chemical composition of the deposits was determined by XPS using a Kratos Axis Ultra DLD with a Hybrid lens mode at $140 \mathrm{~W}$ and pass energy of $20 \mathrm{eV}$ using a monochromatic $\mathrm{Al} \mathrm{K}_{\alpha}$. The Sn 3d, Pd 3d and O 1s XPS core level spectra were analysed using a fitting routine which decomposes each spectrum into individual mixed Gaussian-Lorentzian peaks using a Shirley background subtraction over the energy range of the fit. The binding energy (BE) was corrected using the $\mathrm{C} 1 \mathrm{~s}$ peak at $284.8 \mathrm{eV}$ as an internal standard. The fitting of the $\mathrm{Sn} 3 \mathrm{~d}$ was analysed using doublets with spin orbit splitting (SOS) 8.44 and intensity ratio $\operatorname{Sn} 3 \mathrm{~d}_{5 / 2}: \mathrm{Sn} 3 \mathrm{~d}_{3 / 2}=3 / 2$. The deconvolution of $\mathrm{Pd} 3 \mathrm{~d}$ was performed using doublets with $\mathrm{SOS} 5.3 \mathrm{eV}$ and intensity ratio $\operatorname{Pd} 3 d_{5 / 2}: \operatorname{Pd} 3 d_{3 / 2}=3 / 2,{ }^{42}$ while a peak asymmetry was used in the case of the $\mathrm{Pd} 3 \mathrm{~d}$ peak attributed to the metallic state based on the work of Hüfner et al. ${ }^{43}$

\section{Electrochemical Characterizations}

The electrochemical characterizations of $\mathrm{Pd} / \mathrm{SnO}_{2} / \mathrm{TNT}$ s were carried out in the conventional threeelectrode electrochemical cell made of PTFE at room temperature. The BioLogic VSP potentiostat equipped with the EC-Lab software (BioLogic Science Instruments SAS) was used for electrochemical measurements in $1 \mathrm{M} \mathrm{KOH}$ with and without $1 \mathrm{M} \mathrm{C}_{2} \mathrm{H}_{5} \mathrm{OH}$. The reference electrode used was a $\mathrm{Hg} / \mathrm{HgO}\left(\mathrm{MMO}, E^{\circ}=0.098\right.$ vs $\left.\mathrm{SHE}\right)$, and the counter electrode was a large surface area Pt mesh. Cyclic voltammetry was carried out at a scan rate of $25 \mathrm{mV} \mathrm{s}^{-1}$ unless otherwise stated. Chronoamperograms were performed by holding the potential at $-0.6 \mathrm{~V}$ vs MMO 
for $5 \mathrm{~min}$ and then stepping to $-0.2 \mathrm{~V}$ for $1 \mathrm{~h}$. All the potential are given versus the MMO reference electrode.

\section{RESULTS}

\section{$\mathrm{SnO}_{2}$ deposition onto TNTs}

In order, to optimize the $\mathrm{SnO}_{2}$ deposition different conditions have been investigated, such as the pulse and the purge durations as well as the reactor and the canister temperatures. The influence of those parameters on the growth rate has been studied and adjusted (Fig. S1). In the following, only the $N_{\mathrm{SnO}_{2}}$ was varied to control the thickness of $\mathrm{SnO}_{2}$. SEM top views of TNTs with an increasing number of ALD cycles are shown on Figure $2\left(N_{\mathrm{SnO}_{2}}=0,20,50,100\right.$ and 150 cycles $)$. The typical morphology of bare TNTs grown in an aqueous electrolyte is observed on Figure 2a. The diameter of the nanotubes is about $70 \mathrm{~nm}$, the length is around $1 \mu \mathrm{m}$ and the wall thickness is approximately $10 \mathrm{~nm}$ (additional SEM images are provided in Figure S2). After ALD of $\mathrm{SnO}_{2}$, the wall thickness increases progressively with $N_{\mathrm{SnO} O 2}$ (Figure 2b-e). For 150 ALD cycles the opening of some TNTs is even fully filled by the deposit. The thickness of the film $\left(t_{\mathrm{SnO}_{2}}\right)$ has been measured by spectroscopic ellipsometry on silicon wafers (Figure S1c). It reveals a linear increase of $t_{\mathrm{SnO}_{2}}$ with the number of ALD cycles. A GPC around $1.9 \AA$ Acycle is then calculated from the slope of the straight evolution. This value is in line with the GPC reported previously by Elam et al. ${ }^{31}$ The SEM images show a smooth and homogenous layer of $\mathrm{SnO}_{2}$ onto the TNTs. They suggest a uniform coating of the TNTs but top views do not provide accurate information about the conformity. Thus, cross sectional observations have been performed by TEM.

The Figure 3 shows TEM cross-sections of TNTs after ALD of $\mathrm{SnO}_{2}\left(N_{\mathrm{SnO}_{2}}=100\right.$ cycles $)$. A large view presenting the tube mouth and walls is presented in Figure 3 a where the $\mathrm{TiO}_{2}$ appears as light grey while the $\mathrm{SnO}_{2}$ film corresponds to the darker grey areas (for seek of clarity the $\mathrm{SnO}_{2}$ layer is highlighted in blue). Although the opening of the voids located between the tubes is much smaller than the inner diameter, the din dioxide $\mathrm{SnO}_{2}$ deposition occurs similarly inside and outside the TNTs. The tubes are fully covered by a smooth and continuous layer of $\mathrm{SnO}_{2}$. The thickness of the $\mathrm{SnO}_{2}$ layer is rather constant on the different parts of the tube walls. As seen on Figure 3b, the deposition takes also place conformally at the bottom of the TNTs. The thickness of the $\mathrm{SnO}_{2}$ layer 
in the TNTs is approximately $16 \mathrm{~nm}$. It is in agreement with the value $(19 \mathrm{~nm})$ obtained on plane $\mathrm{Si}$.

The crystalline structure and the chemical composition have been investigated by XRD and XPS. The XRD patterns of as-grown and annealed $\mathrm{SnO}_{2} /$ TNT systems are compared on Figure 4. The diffractogram of the as-grown sample exhibits peaks from the Ti substrate (JCPDS \#00-0441294) and no crystalline $\mathrm{TiO}_{2}$ is detected since the TNTs are usually amorphous after the anodization process. A small contribution from the rutile phase of $\mathrm{SnO}_{2}$ (JCPDS \#00-41-1445), also called cassiterite is also measured at $26.61^{\circ}, 33.91^{\circ}$ and $51.83^{\circ}$ corresponding to the (110), (101) and (211) planes, respectively. After annealing at $450^{\circ} \mathrm{C}$, two additional peaks ascribed to the plane (100) and (002) of the Ti appears at 35.00 and $38.45^{\circ}$, amorphous $\mathrm{TiO}_{2}$ becomes crystalline. The peaks ascribed to the anatase structure (JCPDS \#00-021-1271) are clearly visible at $25.33^{\circ}, 48.08^{\circ}, 53.93^{\circ}, 55.12^{\circ}$ and $62.75^{\circ}$ which are attributed to the $(101),(200),(105),(211)$ and (204) planes, respectively. After the thermal treatment, the diffraction peaks from $\mathrm{SnO}_{2}$ are more intense and the presence of two additional peaks are visible at $37.92^{\circ}$ and $39.00^{\circ}$. They correspond to the planes (200) and (111) of the cassiterite, respectively. The $\mathrm{SnO}_{2}$ peaks are broad. They suggest a relatively small crystallite average size. As expected the survey spectrum of $\mathrm{SnO}_{2} /$ TNTs (shown in Figure S3) contains peaks corresponding to $\mathrm{Sn}, \mathrm{O}$ and $\mathrm{C}$.

The XPS spectrum of Sn 3d is presented in Fig 5a. The peaks centred at 487.1 and $495.5 \mathrm{eV}$ are attributed to $\mathrm{Sn} 3 \mathrm{~d}_{5 / 2}$ and $\mathrm{Sn} 3 \mathrm{~d}_{3 / 2}$, respectively. ${ }^{44-46}$ The deconvolution of the $\mathrm{Sn} 3 \mathrm{~d}$ peaks reveals the existence of tin atoms in the oxidation state $4+$, it can be deduced the presence of stoichiometric $\mathrm{SnO}_{2}$. The spectrum of $\mathrm{O} 1 \mathrm{~s}$ peak is shown on Figure $5 \mathrm{~b}$. It can be deconvoluted with two contributions. The main one, centred at $531 \mathrm{eV}$, is attributed to $\mathrm{O}^{2-}$ in $\mathrm{SnO}_{2}$ and the other one positioned at $532.5 \mathrm{eV}$ is ascribed to adsorbed oxygen or to the presence of water. This analysis confirms the high purity of the deposit and the absence of Ti peaks indicates a good coverage of TNT by ALD of $\mathrm{SnO}_{2}$. In the following, 75 ALD cycles (i.e. approximately $14 \mathrm{~nm}$ ) have systematically been used to grow $\mathrm{SnO}_{2}$ on TNTs. The resulting $\mathrm{SnO}_{2} / \mathrm{TNT}$ s were either used as-grown or after an annealing at $T=450^{\circ} \mathrm{C}$.

\section{Palladium deposition}

The morphology of the Pd particles deposited onto as-grown $\mathrm{SnO}_{2} / \mathrm{TNT}$ s has been observed by SEM. As shown in the previous part for tin diexide $\mathrm{SnO}_{2}, \mathrm{ALD}$ is commonly used to grow 
continuous films. Though the SEM top view (Figure 6a) shows Pd nanoparticles uniformly spread onto the $\mathrm{SnO}_{2}$ /TNTs and not a continuous metallic film.

This phenomenon is expected since there is a high difference of surface energies between the metal and the oxide ${ }^{47}$ A similar island-growth mechanism has been observed for Pt deposited by ALD onto $\mathrm{SnO}_{2}$ nanowires by Lin et al. ${ }^{48}$ The deposition of $\mathrm{Pd}$ is homogenous along the outer wall of the $\mathrm{SnO}_{2} /$ TNTs (Fig 6b). It indicates the deposition of the nanoparticles proceeds within the narrow interstitial voids but these SEM observations give no evidence of Pd deposition inside the tubes. A similar morphology has been reported previously for direct ALD of Pd onto TNTs. ${ }^{16}$ However when the TNTs are covered by the $\mathrm{SnO}_{2}$ film, the geometry of the palladium catalysts appear more uniform. ${ }^{8}$ It is well known that the nature of the substrate influences the ALD of metals. The ALD of $\mathrm{Pd}$ on $\mathrm{ZnO}$ and $\mathrm{Al}_{2} \mathrm{O}_{3}$ has, indeed, revealed that $\mathrm{Pd}$ grows faster on $\mathrm{ZnO}$ but a better uniformity is observed on $\mathrm{Al}_{2} \mathrm{O}_{3} .{ }^{49}$ TEM observations have been performed to investigate the Pd deposition within the TNTs. Fig 7a shows a cross sectional view of a $\mathrm{TiO}_{2}$ nanotube after successive depositions of $\mathrm{SnO}_{2}$ and $\mathrm{Pd}\left(N_{\mathrm{SnO}_{2}}=75\right.$ cycles and $N_{\mathrm{Pd}}=500$ cycles $)$. Similarly to Figure 3 , the $\mathrm{SnO}_{2}$ layer appears in dark grey and coats the entire TNTs. Fig 7a demonstrates that the Pd particles uniformly cover the inner walls of the $\mathrm{SnO}_{2} / \mathrm{TNTs}$. The TEM top view (Figure 7b) confirms the presence of the nanoparticles on both sides of the tube walls. The high-resolution view (Figure 7c) reveals the atomic planes of the palladium catalysts and confirms therefore their crystalline structure. The SAED achieved on $\mathrm{Pd}$ deposited onto annealed $\mathrm{SnO}_{2} / \mathrm{TNT}$ is presented in Figure $7 \mathrm{~d}$. The pattern is composed by numerous spots and rings. The diffuse rings are attributed to a small amount of $\mathrm{SnO}_{2}$, the presence of intense spots on the rings can be attributed to larger crystallite size. The other spots are attributed to the Pd and the anatase phase. The indexation of the different phases is presented in Figure S6. All the main diffraction planes are visible for the three phases and no preferential orientation is noticed.

It is well known that the growth of metallic particles can be affected by the chemical nature and the crystalline structure of the support. ${ }^{50-51}$ The comparison of the ALD of Pd on bare and $\mathrm{SnO}_{2}$-covered TNTs illustrates this effect. While an incubation delay ( $N_{\mathrm{Pd}}=400$ cycles) is observed when depositing Pd on bare TNTs, ${ }^{16}$ active particles are grown on $\mathrm{SnO}_{2}$ for a lower number of ALD cycles since an electroactivity is measured for $N_{\mathrm{Pd}}=100$ cycles (see Figure 9). This can be explained by the action of the formaldehyde that reduces the $\mathrm{SnO}_{2}$ during the second step of the ALD cycle. The XPS measurements that have been performed on $\mathrm{Pd} / \mathrm{SnO}_{2} / \mathrm{TNT}$ s before and after 
electrochemical characterizations show indeed a modification of the chemical nature of the top surface (Figure 8). The analysis of the $\mathrm{Sn} 3 \mathrm{~d}_{5 / 2}$ peak, shown in Figure 8c, indicates the reduction of the $\mathrm{SnO}_{2}$ to metallic tin since contribution corresponding to the oxidation state 0 replaces the peak attributed to the oxidation state +4 (a detailed analysis of the XPS plots is given below). As the surface of the support is not an oxide but an ultrathin layer of metallic Sn, the nucleation of stable Pd is facilitated. A slight effect of the thermal treatment performed prior to ALD of Pd is also observed. After annealing, one observed the decrease of the particle diameter (e. g.: $d_{\mathrm{Pd}}$ varies from 10 to $6 \mathrm{~nm}$ for $N_{\mathrm{Pd}}=600$ cycles, see Figure S4) while the particle density (e. g.: $n_{\mathrm{Pd}}$ varies from $6.310^{9}$ to $14.210^{9}$ particles per $\mathrm{cm}^{2}$ for $N_{\mathrm{Pd}}=600$ cycles) is increased. It suggests that the $\mathrm{Pd}$ nucleation proceed more easily on crystallized substrate.

XPS measurements were performed before and after the electrochemical measurements (EC), on annealed $\mathrm{Pd} / \mathrm{SnO}_{2} / \mathrm{TNTs}$, in order to obtain a better insight into the surface chemical composition of the samples. The analysis of the survey (Figure 8a) shows that, in sample before electrochemical measurements, $\mathrm{C}, \mathrm{O}, \mathrm{Sn}$ and Pd were detected while no Ti was detected due to the attenuation of its signal from the overlayers. The carbon contribution may be attributed to surface contamination or residual carbon from the precursor. ${ }^{52}$ Additionally the $\mathrm{O} 1 \mathrm{~s}$ peak is overlapped by the $\mathrm{Pd} 3 \mathrm{p}_{3 / 2}$ making its interpretation rather not straightforward. The deconvoluted $\mathrm{Pd} 3 \mathrm{~d}$ and Sn $3 d_{5 / 2}$ before the EC are shown in Figure $8 b$ and $8 c$. The analysis of the $P d 3 d_{5 / 2}$ peak (Figure $8 b$ ) reveals the existence of two peaks at 335.5 and $337.5 \mathrm{eV}$. One, located at the lower binding energy, is attributed to palladium atoms in the metallic state while the one, at higher binding energy, is characteristic of $\mathrm{Pd}^{4+}$ in $\mathrm{PdO}_{2} \cdot{ }^{53}$ The ratio of relative intensities of the two components $\mathrm{Pd}^{0}: \mathrm{Pd}^{4+}$ is 93:7 showing that $\mathrm{Pd}$ is mainly in the metallic state. This is slightly different from the analysis of Pd particles grown on TNTs where only metallic Pd has been observed. On the other hand, the analysis of the $\operatorname{Sn} 3 d_{5 / 2}$ XPS peak shows the existence of three components at 485.1, 486.1 and $487.2 \mathrm{eV}$ attributed to $\mathrm{Sn}^{0}, \mathrm{Sn}^{2+}$ and $\mathrm{Sn}^{4+} .54-55$ The relative intensities of the three components $\mathrm{Sn}^{0}: \mathrm{Sn}^{2+}: \mathrm{Sn}^{4+}$ are 75.0:12.4:12.6. The high amount of $\mathrm{Sn}^{0}$ was not expected but it can be explained by deposition method of Pd. During the ALD of Pd, the formalin, a reductive precursor, can reduce the tin species at the surface from $\mathrm{Sn}^{4+}$ to $\mathrm{Sn}^{0}$. This phenomenon is different from what has been previously observed on bare TNT surface.$^{16}$ As predicted by the Ellingham diagram, ${ }^{56}$ it indicates that $\mathrm{SnO}_{2}$ is less stable than $\mathrm{TiO}_{2}$ toward the reduction by formalin. The metallic tin is essentially 
localized at the top surface of the film, around $2 \mathrm{~nm}$, which corresponds to the escape depth of the photoelectrons during the XPS experiments. The SAED performed on the $\mathrm{Pd} / \mathrm{SnO}_{2} / \mathrm{TNT}$ s have, however, confirmed that the bulk material is composed by $\mathrm{SnO}_{2}$ (Figure 7d).

After the electrochemical measurements, the analysis of the survey (Figure 8a') shows that C, Sn and Pd are still detected but the intensities are notably lower. After the EC, a significant amount of potassium is detected on the surface as indicated by the $\mathrm{K} 2 \mathrm{p}$ peak around $293.4 \mathrm{eV}$. The deconvolution of the $\mathrm{Pd} 3 \mathrm{~d}$ peak (Figure 8b') reveals that beyond the component at lower BEs $\left(\mathrm{Pd} 3 \mathrm{~d}_{5 / 2}: 335.1 \mathrm{eV}\right)$ due to metallic Pd, two additional peaks are present at higher BEs (336 and $337.1 \mathrm{eV}$ ). These two peaks are attributed to palladium in the $2+$ and $4+$ oxidation states related to $\mathrm{PdO}$ and $\mathrm{PdO}_{2}$ and/or hydroxides. ${ }^{57-58}$ The relative intensities of the three components $\mathrm{Pd}: \mathrm{Pd}^{2+}: \mathrm{Pd}^{4+}$ is now 39.8:41.1:19.1. It is therefore evident that after the electrochemical measurements, oxidation of palladium has taken place as well and around $60 \%$ of the detected signal is due to oxygenated species. At this point we cannot exclude the formation of surface complexes that contains potassium as well, the $\mathrm{K} 2 \mathrm{p}_{3 / 2}$ is detected around $293.4 \mathrm{eV}$. In the literature, this binding energy is reported for potassium atoms in ionic compounds and $\mathrm{K} / \mathrm{Pd} .{ }^{47} \mathrm{It}$ is also well-known that all alkali metals, including potassium, form oxopalladates $\left(\mathrm{K}_{n} \mathrm{PdO}_{\mathrm{m}}\right) .{ }^{59}$ The formation of this complex could explain the decrease of the signal from C, Sn and Pd. Further investigation is necessary to obtain a better insight of the K-based surface species. The analysis of the $\mathrm{Sn} 3 \mathrm{~d}_{5 / 2}$ shows the existence of only one component at $487.2 \mathrm{eV}$, due to $\mathrm{SnO}_{2} .{ }^{54}$

\section{Electrocatalytic activity}

Electrochemical response in $\mathbf{K O H}$ - Figure 9 shows cyclic voltammograms of $\mathrm{Pd} / \mathrm{SnO}_{2} / \mathrm{TNT}$ electrocatalysts and $\mathrm{SnO}_{2} / \mathrm{TNT}$ support without $\mathrm{Pd}$ in $1 \mathrm{M} \mathrm{KOH}$. The current density of the bare support is very low indicating, thus, no catalytic activity. The CVs of various Pd loads exhibit the characteristic peaks of $\mathrm{Pd}$ oxidation (ca. $-0.2 \mathrm{~V}$ ) and reduction (ca. $-0.25 \mathrm{~V}$ ). The region of hydrogen adsorption, absorption and desorption is visible at more negative potentials. The current density (per geometric area) rises with increasing the number of ALD cycles up to 500 cycles and then decreases because the coalescence of the Pd particles begins. It should be noted that in our previous work carried out on Pd/TNTs, neither oxidation nor reduction peaks of Pd were observed on CVs performed in $1 \mathrm{M} \mathrm{KOH}$ for $\mathrm{NPd}<500$ cycles. ${ }^{16}$ Conversely, $\mathrm{SnO}_{2}$-covered TNTs exhibit an electrochemical response for a Pd loading as low as 100 ALD cycles. This confirms that stable 
Pd nuclei are formed on such substrate at low $N_{\mathrm{Pd}}$. As mentioned above, this can be ascribed to the reduction of the $\mathrm{SnO}_{2}$ to metallic tin at the top surface. The enhancement of the current response can also be attributed to the high electronic conductivity of $\mathrm{SnO}_{2}$ (here $10^{-3}-10^{-2} \Omega \mathrm{cm}$ while Tighineanu et al. ${ }^{60}$ have reported $10^{3}-10^{4} \Omega \mathrm{cm}$ for TNTs) that allows efficiently interconnect highly dispersed $\mathrm{Pd}$ nanoparticles and to MSI interaction between $\mathrm{Pd}$ and $\mathrm{SnO}_{2}$.

Ethanol electrooxidation on $\mathbf{P d} / \mathrm{SnO}_{2} / \mathrm{TNT}$ : effect of the annealing - In order to compare the intrinsic electrocatalytic activity of $\mathrm{Pd} / \mathrm{SnO}_{2} / \mathrm{TNT}$ samples, the current densities were normalized with respect to the electrochemical surface area (ECSA) that is estimated using PdO reduction peak in $0.5 \mathrm{M} \mathrm{H}_{2} \mathrm{SO}_{4}$, as reported previously. ${ }^{16,61}$ The ECSA was measured on as-grown and annealed $\mathrm{SnO}_{2} / \mathrm{TNTs}$ with different Pd loads and the values are plotted in Figure S5. It is found that the ECSA increases with $N_{\mathrm{Pd}}$ and drops after reaching a maximum. Such evolution is measured for both as-grown and annealed samples but the active area is significantly lower after annealing. This is despite the lower particle size (ca. $2 \times$ lower) and the higher number of particles (ca. $2 \times$ higher), observed for all samples after annealing. ${ }^{62}$ This trend is rather unusual, because one would expect the higher number of active surface atoms for the smaller particles in comparison to the larger ones. Furthermore, Sun et al. showed that the crystalline $\mathrm{SnO}_{2}$, after annealing increased the ECSA if compared to amorphous $\mathrm{SnO}_{2}$ in as-grown sample, however no morphological difference was found on Pt particles. ${ }^{63}$ In the present case, the evolution of the ECSA seems to be solely related to geometric considerations. Thus the expansion of the ECSA with $N_{\mathrm{Pd}}$ can be attributed to the enlargement of the Pd particles (i. e. the rise of their geometric area) while the sudden decrease can be ascribed to their coalescence. The observed decrease of ECSA after annealing could be related to the interaction between $\mathrm{SnO}_{2}$ and $\mathrm{Pd}$ nanoparticles leading to the partial coverage of Pd surface by oxygenated species from $\mathrm{SnO}_{2}$. When Pd is supported on $\mathrm{SnO}_{2}$ the electronic type MSI may raise at the interface of the two solids due to the charge transfer from the support to $\mathrm{Pd}$ (from the solid with lower work function (WF) to the solid with higher WF) and/or the higher availability of hydroxyl ions from $\mathrm{SnO}_{2}$ that adsorb on the catalyst surface leading to lower ECSA, however these oxygenated species could have a promotional effect on ethanol electrooxidation. ${ }^{53}$

Figure 10 shows the CVs of as-grown and annealed $\mathrm{SnO}_{2} / \mathrm{TNT}$ with 500 ALD cycles Pd in $1 \mathrm{M}$ $\mathrm{KOH}+1 \mathrm{M} \mathrm{C}_{2} \mathrm{H}_{5} \mathrm{OH}$. The current density is higher for Pd deposited on the annealed support in the whole range of the anodic potential. The current density increases until it reaches a maximum at 
0.251 and $0.275 \mathrm{~V}$ for as-grown and the annealed samples, respectively. The decrease of the current density is due to the surface palladium oxide formation, ${ }^{64}$ which is not active for ethanol electrooxidation. On the reverse scan, the Pd activity is recovered at -0.19 and $-0.24 \mathrm{~V}$ for asgrown and the annealed samples, respectively, due to $\mathrm{PdO}_{\mathrm{x}}$ reduction to metallic $\mathrm{Pd}$. The current density is much higher for Pd grown on annealed $\mathrm{SnO}_{2} / \mathrm{TNT}$ and the onset potential is shifted negatively, -0.5 and $-0.6 \mathrm{~V}$ for Pd deposited on as-grown and annealed supports, respectively. The increasing of the catalytic activity can be attributed to several factors: the increased conductivity of both oxides $\left(\mathrm{SnO}_{2} / \mathrm{TiO}_{2}\right)$ after annealing and MSI effect. ${ }^{62}$ Chen et al. have demonstrated an easier $\mathrm{CO}$ oxidation on crystalline $\mathrm{Pt} / \mathrm{SnO}_{2}$, suggesting a stronger interaction between $\mathrm{Pt}$ and crystalline $\mathrm{SnO}_{2}$ than between $\mathrm{Pt}$ and amorphous $\mathrm{SnO}_{2}$ support. ${ }^{63}$ As shown previously, ${ }^{16}$ the Pd particles deposited on annealed TNTs support exhibited a higher catalytic activity for ethanol electrooxidation reaction (as seen thereinafter, in Figure 13a, the maximum current ratio is higher than 4).

Ethanol electrooxidation on annealed $\mathrm{Pd} / \mathrm{SnO}_{2} / \mathrm{TNT}$ : effect of the Pd charge - Figure 11a shows the linear sweep voltammetry (LSV) of the annealed $\mathrm{SnO}_{2} / \mathrm{TNT}$ with different amount of $\operatorname{Pd}\left(N_{\mathrm{Pd}}=300,400,500,600,800\right.$ cycles $)$ in the ethanol containing electrolyte. The current density for ethanol electrooxidation increased with the number of ALD cycles up to 500 cycles and then the decrease occurred. This is illustrated in Figure $11 \mathrm{~b}$ where the current density at $-0.2 \mathrm{~V}$ is plotted against the $N_{\mathrm{Pd}}$. This evolution indicates that from 300 to 500 ALD cycles the amount of available active sites for ethanol electrooxidation increases with the number of ALD cycles while at higher number of cycles, the increase of the particles size and the particle coalescence reduce the catalytic activity. Moreover, the MSI effect between $\mathrm{Pd}$ and $\mathrm{SnO}_{2}$ may weaken as the particles become larger thus contributing to the decrease in the rate of electrooxidation. ${ }^{65}$

A similar behaviour was reported in a previous work, where the catalytic activity of 500 cycles of $\mathrm{Pd}$ deposited on TNTs was the highest. Chronoamperograms at $-0.2 \mathrm{~V}$ for various loading of Pd interfaced with annealed $\mathrm{SnO}_{2} /$ TNT are presented on the Figure 12. The initial current density and the order of activities are in agreement with LSV results. For the samples with 300 and 800 cycles of $\mathrm{Pd}$, the current density is low at the beginning 0.23 and $0.07 \mathrm{~mA} \mathrm{~cm}^{-2}$, respectively. Then it decreases quickly until it reaches a steady-state at 0.16 and $0.05 \mathrm{~mA} \mathrm{~cm}^{-2}$, respectively. For the samples with 400, 500, 600 cycles the current density is higher at the beginning $0.35,0.40$ and 
$0.27 \mathrm{~mA} \mathrm{~cm}^{-2}$, respectively and continuously decreases without reaching a steady state after $1 \mathrm{~h}$. The current percentage loss (without double layer correction) is 32, 50, 55, 45 and $34 \%$ for 300 , 400, 500, 600 and 800 cycles of $\mathrm{Pd}$, respectively. The current decrease is attributed to $\mathrm{Pd}$ oxide and oxopalladate formation as found from XPS analysis on the catalyst after electrochemical measurements (Fig. 8).

\section{Ethanol electrooxidation: effect of the chemical nature and the crystalline structure of the}

support - Figure 13a compares the effect of the chemical nature of the support and the annealing for 500 cycles $\mathrm{Pd} / \mathrm{SnO}_{2} / \mathrm{TNT}$ catalyst. In order to compare the present results with literature, the $\mathrm{Pd}$ load (i. e., the mass of Pd, $m_{\mathrm{Pd}}$, per area unit) has been estimated from the ECSA and the $d_{\mathrm{Pd}}$. The LSVs of Pd deposited on as-grown TNTs, annealed TNTs, as-grown $\mathrm{SnO}_{2} / \mathrm{TNT}$ s and annealed $\mathrm{SnO}_{2} / \mathrm{TNTs}$ show that annealing and addition of $\mathrm{SnO}_{2}$ interlayer enhance the ethanol electrooxidation. The positive effect of the support annealing has already been shown on bare TNTs ${ }^{16}$ and is further confirmed in this work for $\mathrm{SnO}_{2}$-covered TNTs. Since the morphology of the structured support is not significantly modified after the deposition of the thin $\mathrm{SnO}_{2}$ layer $\left(N_{\mathrm{SnO}_{2}}=75\right.$ cycles $)$, the evolution of the electrochemical response can not be attributed to geometric considerations. The LSVs of the as-grown TNTs and $\mathrm{SnO}_{2} / \mathrm{TNT}$ s catalysts with 500 cycles $\mathrm{Pd}$ clearly show that addition of $\mathrm{SnO}_{2}$ interlayer increases the current density of ethanol electrooxidation. The current density is significantly higher for $\mathrm{Pd}$ on $\mathrm{SnO}_{2} / \mathrm{TNT}$ s than for Pd/TNTs and the onset potential is shifted negatively from -0.26 to $-0.45 \mathrm{~V}$ for as-grown TNTs and $\mathrm{SnO}_{2} /$ TNTs, respectively.

This is in line with previous reports for $\mathrm{Pt}$ and $\mathrm{Pd}$ catalysts where $\mathrm{SnO}_{2}$ showed strong contribution towards the improved catalytic activity of the metal. ${ }^{66-67}$ For instance, Ruiz et al.${ }^{62}$ have shown that $\mathrm{Pt}-\mathrm{SnO}_{2}-\mathrm{C}$ has higher activity for methanol electrooxidation as compared to $\mathrm{Pt}-\mathrm{TiO}_{2}-\mathrm{C}$. The high catalytic activity was attributed to the smaller Pt particle size obtained on $\mathrm{SnO}_{2}-\mathrm{C}$ support. Moreover, Kim et al. have proposed a mechanism in which $\mathrm{SnO}_{2}$ facilitates the oxidative removal of the intermediates residues on $\mathrm{Pt}$ for alcohol electrooxidation. ${ }^{68}$ The addition of Sn species on $\mathrm{Pt}$ modifies its electronic environment by influencing the electron affinities of the surface Pt atoms and produces surface oxygenated species which can act as an oxidant source, thereby increasing stability through efficient oxidation of surface poisoning species. An et al. have reported that the catalytic activity of $\mathrm{Pd}$ has been enhanced by $\mathrm{SnO}_{2}$ addition on $\mathrm{TiO}_{2}-\mathrm{MWCT}$ for ethanol and 
methanol electrooxidation. ${ }^{20}$ This improvement is due to better particles dispersion and improvement of the resistance level to $\mathrm{CO}$ poisoning for methanol electrooxidation due to the increase of the concentration of $\mathrm{OH}_{\mathrm{ads}}$ species on the Pd surface, which promotes the oxidation of acetaldehyde thus releasing active sites for the reaction. ${ }^{22}$

This effect is also visible by comparing annealed $\mathrm{SnO}_{2} /$ TNTs with annealed TNTs. The current density is further increased for annealed $\mathrm{SnO}_{2} / \mathrm{TNT}$ support. Furthermore, Figure 13b shows a comparison of the current density obtained for 500 cycles of Pd on different supports at $-0.2 \mathrm{~V}$. As can be seen, the highest current density is obtained for annealed $\mathrm{SnO}_{2} / \mathrm{TNT}$ with 500 cycles of Pd due to the increased conductivity of both oxides $\left(\mathrm{SnO}_{2} / \mathrm{TiO}_{2}\right)$ after annealing, and to the metalsupport interaction between $\mathrm{Pd}$ and $\mathrm{SnO}_{2}$. The size of $\mathrm{Pd}$ clusters is smaller when grown on annealed $\mathrm{SnO}_{2}$ (for $N_{\mathrm{Pd}} \approx 600$ cycles, $d_{\mathrm{Pd}} \approx 10 \mathrm{~nm}$ and $d_{\mathrm{Pd}} \approx 6 \mathrm{~nm}$ for as-grown and annealed $\mathrm{SnO}_{2} / \mathrm{TiO}_{2}$, respectively). The smaller Pd particles may result in the stronger MSI effect. The MSI effect occurs at the interface of the two solids with different work function (WF): 5.2-5.6 and $4.6 \mathrm{eV}$ for $\mathrm{Pd}$ and $\mathrm{SnO}_{2}$, respectively. ${ }^{69}$ The difference in $\mathrm{WF}$ will result in the charge transfer from the solid with lower WF to the solid with the higher one. The modification of electronic properties of Pd due to the charge transfer from the support and higher availability of oxygenated species or hydroxyl ions $\left(\mathrm{OH}^{-}\right)$from $\mathrm{SnO}_{2}$ to $\mathrm{Pd}$, results in the higher catalytic activity of $\mathrm{Pd} / \mathrm{SnO} \mathrm{T}_{2} / \mathrm{TNT}$.

Figure 14 compares of the activity of the best result of the present study (i. e. $\mathrm{Pd} / \mathrm{SnO}_{2} / \mathrm{TNT}^{2}$, $N_{\mathrm{Pd}}=500$ cycles after annealing) with similar systems reported in literature. The Pd particles are grown by various methods (electrochemical deposition, electrochemical deposition and milling, chemical deposition or ALD) on TNTs, carbon black, or multiwall CNTs. In some cases, the substrates are covered by $\mathrm{SnO}_{2}$. Note that the experimental conditions (i. e. electrolyte composition and scanning rate, see Figure S7) are not exactly identical in all cases but sufficiently closed to be compared. Although the conditions are not advantageous for the present study, the measured activity is very closed to the best reported in literature. ${ }^{70}$ The current density as well as the potential of the forward peak are better than on bare TNTs. ${ }^{16}$ The comparison also suggests that $\mathrm{SnO}_{2}$ seems to be a more efficient substrate to promote the electroactivity of Pd nanoparticles toward ethanol oxidation. 


\section{CONCLUSION}

In this work, it has been shown that ALD was successfully used to functionalize TNTs with $\mathrm{SnO}_{2}$ layer and Pd nanoparticles for ethanol electrooxidation. The depositions of both $\mathrm{SnO}_{2}$ and $\mathrm{Pd}$, are fully controlled and perfectly conformal onto the TNTs. The ALD of Pd on $\mathrm{SnO}_{2}$-covered TNTs is facilitated because the top surface is reduced to metallic tin during the deposition of the particles. This synthesis method allows comparing the catalytic activity of Pd nanoparticles toward ethanol electrooxidation on different supports with no significant modification of the three-dimensional geometry. First, the modification of the chemical nature of the support has been investigated by the ALD of $\mathrm{SnO}_{2}$ as an interlayer in between TNTs and Pd. The comparison between $\mathrm{SnO}_{2}$ and $\mathrm{TiO}_{2}$ surface has revealed that the $\mathrm{SnO}_{2}$ has a promotional effect on Pd catalytic activity for ethanol electrooxidation. The positive impact of the addition of Sn species on Pd catalyst is well known and it is confirmed in this study. This fact can be attributed to several effects (i) the $\mathrm{SnO}_{2}$ layer can facilitate the $\mathrm{OH}$ adsorption, (ii) the $\mathrm{SnO}_{2}$ extreme surface is reduced to metallic Sn during ALD of Pd which favour the Pd growth and thereby the adsorption and the oxidation of ethanol are accelerated and (iii) MSI between $\mathrm{Pd}$ and $\mathrm{SnO}_{2}$. Second, the influence of the crystalline structure of the support has been studied. The annealing of the support improves the electrocatalytic properties of Pd. According to this result the promoting effect can be attributed to several aspects: (i) the increased conductivity of the support by the annealing and (ii) MSI effect. The effect of the charge of Pd had also been investigated by varying the number of Pd ALD cycles. The best catalytic activity has been obtained for 500 ALD cycles on annealed $\mathrm{SnO}_{2} /$ TNTs. The electrochemical characterizations on such $\mathrm{Pd} / \mathrm{SnO}_{2} / \mathrm{TNT}$ s systems have evidenced a high current density and low onset potential compared to literature and commercial catalyst. In future studies, it would be interesting to investigate the catalytic properties of $\mathrm{Pd}$ deposited on $\mathrm{SnO}_{2}$ nanotubes without $\mathrm{TiO}_{2}$ and to investigate the potential effect of the deposition of a thin protective layer to stabilize the $\mathrm{Pd}$ activity for long term use. A recent study has shown that ALD of $\mathrm{SnO}_{2}$ can be used on nanoparticles to enhance Pt catalytic durability for fuel cell application. ${ }^{71}$ 


\section{ACKNOWLEDGEMENTS}

The authors acknowledge V. Heresanu (CINaM) for XRD measurements, D. Chaudanson and S. Nitsche (CINaM) for their valuable help with the electron microscopy. A. Baronnet (CINaM) is also acknowledged for fruitful discussions. R. Sinha Roy and Y Magnin are acknowledged (CINaM) for helping in graphics editing. This collaborative work was supported by the France-

Canada Research Fund. M. K. S. Barr and L. Assaud are indebted to the Conseil Régional Provence-Alpes-Côte d'Azur and the CNRS for the PhD grants.

\section{ASSOCIATED CONTENT}

Supporting Information. Influence of ALD parameter on the growth of $\mathrm{SnO}_{2}$ thin layer. SEM pictures of bare $\mathrm{TiO}_{2}$ nanotubes. XPS survey TNTs after ALD of $\mathrm{SnO}_{2}$. Morphology of Pd nanoparticles grown onto $\mathrm{SnO}_{2}$-covered $\mathrm{TiO}_{2}$ nanotubes. Evolution of the ECSA with $N_{\mathrm{Pd}}$. SAED indexation of $\mathrm{SnO}_{2} / \mathrm{TNT}$ annealed after ALD of Pd. Experimental conditions of the CVs from which the forward ethanol electrooxidation peak current and potential are extracted. This material is available free of charge via the Internet at http://pubs.acs.org.

\section{AUTHOR INFORMATION}

\section{Corresponding Authors}

*To whom correspondence should be addressed: elena.baranova@uottawa.ca; lionel.santinacci@univ-amu.fr 


\section{REFERENCES}

(1) Rousseau, S.; Coutanceau, C.; Lamy, C.; Leger, J. M., Direct Ethanol Fuel Cell (DEFC): Electrical Performances and Reaction Products Distribution under Operating Conditions with Different Platinum-Based Anodes. J. Power Sources 2006, 158, 18-24.

(2) Antolini, E., Catalysts for Direct Ethanol Fuel Cells. J. Power Sources 2007, 170, 1-12.

(3) Bianchini, C.; Shen, P. K., Palladium-Based Electrocatalysts for Alcohol Oxidation in Half Cells and in Direct Alcohol Fuel Cells. Chem. Rev. 2009, 109, 4183-4206.

(4) Antolini, E.; Gonzalez, E. R., Alkaline Direct Alcohol Fuel Cells. J. Power Sources 2010, 195, 3431-3450.

(5) Bambagioni, V.; Bianchini, C.; Marchionni, A.; Filippi, J.; Vizza, F.; Teddy, J.; Serp, P.; Zhiani, M., Pd and Pt-Ru Anode Electrocatalysts Supported on Multi-Walled Carbon Nanotubes and Their Use in Passive and Active Direct Alcohol Fuel Cells with an Anion-Exchange Membrane (Alcohol = Methanol, Ethanol, Glycerol). J. Power Sources 2009, 190, 241-251.

(6) Feng, Y.-Y.; Liu, Z.-H.; Xu, Y.; Wang, P.; Wang, W .-H.; Kong, D.-S., Highly Active PdAu Alloy Catalysts for Ethanol Electro-Oxidation. J. Power Sources 2013, 232, 99-105.

(7) Monyoncho, E. A.; Ntais, S.; Soares, F.; Woo, T. K.; Baranova, E. A., Synergetic Effect of Palladium-Ruthenium Nanostructures for Ethanol Electrooxidation in Alkaline Media. $J$. Power Sources 2015, 287, 139-149.

(8) Neto, A. O.; da Silva, S. G.; Buzzo, G. S.; de Souza, R. F. B.; Assumpção, M. H. M. T.; Spinacé, E. V.; Silva, J. C. M., Ethanol Electrooxidation on PdIr/C Electrocatalysts In Alkaline Media: Electrochemical and Fuel Cell Studies. Ionics 2015, 21, 87-495.

(9) Tauster, S. J.; Fung, S. C.; Garten, R. L., Strong Metal-Support Interactions - Group-8 Noble-Metals Supported on $\mathrm{TiO}_{2}$. J. Am. Chem. Soc. 1978, 100, 170-175.

(10) Hepel, M.; Kumarihamy, I.; Zhong, C. J., Nanoporous $\mathrm{TiO}_{2}$-Supported Bimetallic Catalysts for Methanol Oxidation in Acidic Media. Electrochem. Commun. 2006, 8, 1439-1444.

(11) Ntais, S.; Isaifan, R. J.; Baranova, E. A., An X-Ray Photoelectron Spectroscopy Study of Platinum Nanoparticles on Yttria-Stabilized Zirconia Ionic Support: Insight into Metal Support Interaction. Mater. Chem. Phys. 2014, 148, 673-679.

(12) Xu, C. W.; Liu, Y. L.; Yuan, D. S., Pt and Pd Supported on Carbon Microspheres for Alcohol Electrooxidation in Alkaline Media. Int. J. Hydrogen Energy 2007, 2, 674-680.

(13) Zheng, H. T.; Li, Y. L.; Chen, S. X.; Shen, P. K., Effect of Support on the Activity of Pd Electrocatalyst for Ethanol Oxidation. J. Power Sources 2006, 163, 371-375. 
(14) Huang, S. Y.; Ganesan, P.; Park, S.; Popov, B. N., Development of a Titanium DioxideSupported Platinum Catalyst with Ultrahigh Stability for Polymer Electrolyte Membrane Fuel Cell Applications. J. Am. Chem. Soc. 2009, 131, 13898-13899.

(15) Lee, K.; Mazare, A.; Schmuki, P., One-Dimensional Titanium Dioxide Nanomaterials: Nanotubes. Chem. Rev. 2014, 114, 9385-9454.

(16) Assaud, L.; Brazeau, N.; Barr, M. K. S.; Hanbucken, M.; Ntais, S.; Baranova, E. A.; Santinacci, L., Atomic Layer Deposition of Pd Nanoparticles on $\mathrm{TiO}_{2}$ nanotubes for Ethanol Electrooxidation: Synthesis and Electrochemical Properties ACS Appl. Mater. Interfaces 2015, 7, 24533-24542.

(17) Batzill, M.; Diebold, U., The Surface and Materials Science of Tin Oxide. Prog. Surf. Sci. 2005, 79, 47-154.

(18) Wen, Z.; Yang, S.; Liang, Y.; He, W.; Tong, H.; Hao, L.; Zhang, X.; Song, Q., The Improved Electrocatalytic Activity of Palladium/Graphene Nanosheets Towards Ethanol Oxidation by Tin Oxide. Electrochim. Acta 2010, 56, 139-144.

(19) Lu, H.; Fan, Y.; Huang, P.; Xu, D., $\mathrm{SnO}_{2}$ Nanospheres Supported Pd Catalyst with Enhanced Performance for Formic Acid Oxidation. J. Power Sources 2012, 215, 48-52.

(20) An, H.; Pan, L.; Cui, H.; Li, B.; Zhou, D.; Zhai, J.; Li, Q., Synthesis and Performance of Palladium-Based Catalysts for Methanol and Ethanol Oxidation in Alkaline Fuel Cells. Electrochim. Acta 2013, 102, 79-87.

(21) An, H.; Pan, L.; Cui, H.; Li, Q.; Zhai, J., Electrocatalytic Performance of Pd/SnO $2_{2}$ $\mathrm{TiO}_{2} / \mathrm{MWCNT}$ Catalyst for Oxidation of Ethylene Glycol in Alkaline Media. J. Electrochem. Soc. 2014, 162, F123-F128.

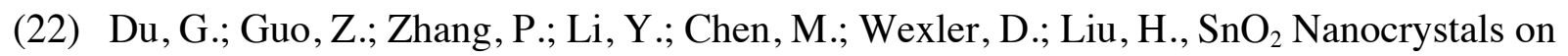
Self-Organized $\mathrm{TiO}_{2}$ Nanotube Array as Three-Dimensional Electrode for Lithium Ion Microbatteries. J. Mater. Chem. 2010, 20, 5689-5694.

(23) Wu, X.; Zhang, S.; Wang, L.; Du, Z.; Fang, H.; Ling, Y.; Huang, Z., Coaxial $\mathrm{SnO}_{2} @ \mathrm{TiO}_{2}$ Nanotube Hybrids: from Robust Assembly Strategies to Potential Application in $\mathrm{Li}^{+}$ Storage. J. Mater. Chem. 2012, 22, 11151-11158.

(24) Hu, J.; Liu, Q.; Zhang, H.; Chen, C.-D.; Liang, Y.; Du, R.-G.; Lin, C.-J., Facile Ultrasonic Deposition of $\mathrm{SnO}_{2}$ Nanoparticles on $\mathrm{TiO}_{2}$ Nanotube Films for Enhanced Photoelectrochemical Performances. J. Mater. Chem. A 2015, 3, 22605-22613.

(25) Turkevych, I.; Kosar, S.; Pihosh, Y.; Mawatari, K.; Kitamori, T.; Ye, J.; Shimamura, K., Synergistic Effect between $\mathrm{TiO}_{2}$ and Ubiquitous Metal Oxides on Photocatalytic Activity of Composite Nanostructures. J. Ceram. Soc. Jpn. 2014, 122, 393-397. 
(26) Jere, T.; Marianna, K.; Emma, H.; Mikko, R.; Markku, L., Preparation of regularly structured nanotubular $\mathrm{TiO}_{2}$ thin films on ITO and their modification with thin ALD-grown layers. Nanotechnology 2012, 23, 125707.

(27) Zazpe, R.; Kraut, M.; Sopha, H.; Hromadko, L.; Albert, M.; Prikryl, J.; Gartnerova, V.; Bartha, J. W.; Macak, J. M., Atomic Layer Deposition for Coating of High Aspect Ratio $\mathrm{TiO}_{2}$ Nanotube Layers. Langmuir 2016, 32, 10551-10558.

(28) Sarkar, S. K.; Kim, J. Y.; Goldstein, D. N.; Neale, N. R.; Zhu, K.; Elliott, C. M.; Frank, A. J.; George, S. M., $\mathrm{In}_{2} \mathrm{~S}_{3}$ Atomic Layer Deposition and Its Application as a Sensitizer on $\mathrm{TiO}_{2}$ Nanotube Arrays for Solar Energy Conversion. J. Phys. Chem. C 2010, 114, 8032-8039.

(29) Macak, J. M.; Prikryl, J.; Sopha, H.; Strizik, L., Antireflection $\ln _{2} \mathrm{O}_{3}$ Coatings of SelfOrganized $\mathrm{TiO}_{2}$ Nanotube Layers Prepared by Atomic Layer Deposition. Phys. Status Solidi RRL 2015, 9, 516-520.

(30) Elam, J. W.; Baker, D. A.; Martinson, A. B. F.; Pellin, M. J.; Hupp, J. T., Atomic Layer Deposition of Indium Tin Oxide Thin Films Using Nonhalogenated Precursors. J. Phys. Chem. C 2008, 112, 1938-1945.

(31) Elam, J. W.; Baker, D. A.; Hryn, A. J.; Martinson, A. B. F.; Pellin, M. J.; Hupp, J. T., Atomic Layer Deposition of Tin Oxide Films Using Tetrakis(Dimethylamino) Tin. J. Vac. Sci. Technol. A 2008, 26, 244-252.

(32) Mullings, M. N.; Hägglund, C.; Bent, S. F., Tin Oxide Atomic Layer Deposition from Tetrakis(Dimethylamino)Tin and Water. J. Vac. Sci. Technol. A 2013, 31, 061503.

(33) Detavernier, C.; Dendooven, J.; Pulinthanathu Sree, S.; Ludwig, K. F.; Martens, J. A., Tailoring Nanoporous Materials by Atomic Layer Deposition. Chem. Soc. Rev. 2011, 40, 52425253.

(34) Elam, J. W.; Dasgupta, N. P.; Prinz, F. B., ALD for Clean Energy Conversion, Utilization, and Storage. MRS Bulletin 2011, 36, 899-906.

(35) Weber, M. J.; Mackus, A. J. M.; Verheijen, M. A.; van der Marel, C.; Kessels, W. M. M., Supported Core/Shell Bimetallic Nanoparticles Synthesis by Atomic Layer Deposition. Chem. Mater. 2012, 24, 2973-2977.

(36) Lu, J.; Elam, J. W.; Stair, P. C., Synthesis and Stabilization of Supported Metal Catalysts by Atomic Layer Deposition. Acc. Chem. Res. 2013, 46, 1806-1815.

(37) Goldstein, D. N.; George, S. M., Enhancing the Nucleation of Palladium Atomic Layer Deposition on $\mathrm{Al}_{2} \mathrm{O}_{3}$ Using Trimethylaluminum to Prevent Surface Poisoning by Reaction Products. Appl. Phys. Lett. 2009, 95, 143106.

(38) Feng, H.; Libera, J. A.; Stair, P. C.; Miller, J. T.; Elam, J. W., Subnanometer Palladium Particles Synthesized by Atomic Layer Deposition. ACS Catal. 2011, 1, 665-673. 
(39) Lu, J.; Liu, B.; Greeley, J. P.; Feng, Z.; Libera, J. A.; Lei, Y.; Bedzyk, M. J.; Stair, P. C.; Elam, J. W., Porous Alumina Protective Coatings on Palladium Nanoparticles by Self-Poisoned Atomic Layer Deposition. Chem. Mater. 2012, 24, 2047-2055.

(40) Assaud, L.; Heresanu, V.; Hanbuecken, M.; Santinacci, L., Fabrication of p/n Heterojunctions by Electrochemical Deposition of $\mathrm{Cu}_{2} \mathrm{O}$ onto $\mathrm{TiO}_{2}$ Nanotubes. C. R. Chim. 2013, $16,89-95$.

(41) Assaud, L.; Monyoncho, E.; Pitzschel, K.; Allagui, A.; Petit, M.; Hanbucken, M.; Baranova, E. A.; Santinacci, L., 3D-Nanoarchitectured Pd/Ni Catalysts Prepared by Atomic Layer Deposition for The Electrooxidation of Formic Acid. Beilstein J. Nanotechnol. 2014, 5 , 162-172.

(42) Richter, K.; Peplinski, B., Energy Calibration of Electron Spectrometers. J. Electron. Spectrosc. Relat. Phenom. 1978, 13, 69-71.

(43) Hüfner, S.; Wertheim, G. K., Core-Line Asymmetries in the X-Ray-Photoemission Spectra of Metals. Phys. Rev. B 1975, 11, 678-683.

(44) Meng, X.; Yao, J.; Liu, F.; He, H.; Zhou, M.; Xiao, P.; Zhang, Y., Preparation of $\mathrm{SnO}_{2} @ \mathrm{C}$-Doping $\mathrm{TiO}_{2}$ Nanotube Arrays and Its Electrochemical and Photoelectrochemical Properties. J. Alloys Compd. 2013, 552, 392-397.

(45) Tian, Q.; Zhang, Z.; Yang, L.; Hirano, S., Encapsulation of $\mathrm{SnO}_{2}$ Nanoparticles into Hollow $\mathrm{TiO}_{2}$ Nanowires as High Performance Anode Materials for Lithium Ion Batteries. $J$. Power Sources 2014, 253, 9-16.

(46) Liao, J.-Y.; Manthiram, A., Mesoporous $\mathrm{TiO}_{2}$-Sn/C Core-Shell Nanowire Arrays as High-Performance 3D Anodes for Li-Ion Batteries. Adv. Energy Mater. 2014, 4, 1400403.

(47) Campbell, C. T., Ultrathin Metal Films and Particles on Oxide Surfaces: Structural, Electronic and Chemisorptive Properties. Surf. Sci. Rep. 1997, 27, 1-111.

(48) Lin, Y.-H.; Hsueh, Y.-C.; Lee, P.-S.; Wang, C.-C.; Wu, J. M.; Perng, T.-P.; Shih, H. C., Fabrication of Tin Dioxide Nanowires with Ultrahigh Gas Sensitivity by Atomic Layer Deposition of Platinum. J. Mater. Chem. 2011, 21, 10552-10558.

(49) Feng, H.; Elam, J. W.; Libera, J. A.; Setthapun, W.; Stair, P. C., Palladium Catalysts Synthesized by Atomic Layer Deposition for Methanol Decomposition. Chem. Mater. 2010, 22, 3133-3142.

(50) Lei, Y.; Liu, B.; Lu, J.; Libera, J. A.; Greeley, J. P.; Elam, J. W., Effects of Chlorine in Titanium Oxide on Palladium Atomic Layer Deposition. J. Phys. Chem. C 2014, 118, 2261122619.

(51) Mackus, A. J. M.; Matthieu, J. W., M. J.; Thissen, N. F. W.; Garcia-Alonso, D.; Vervuurt, R. H. J.; Assali, S.; Bol, A. A.; Verheijen, M. A.; Kessels, W. M. M., Atomic Layer 
Deposition of Pd and Pt Nanoparticles for Catalysis: on The Mechanisms of Nanoparticle Formation. Nanotechnology 2016, 27, 034001.

(52) Gharachorlou, A.; Detwiler, M. D.; Nartova, A. V.; Lei, Y.; Lu, J.; Elam, J. W.; Delgass, W. N.; Ribeiro, F. H.; Zemlyanov, D. Y., Palladium Nanoparticle Formation on $\mathrm{TiO}_{2}(110)$ by Thermal Decomposition of Palladium(II) Hexafluoroacetylacetonate. ACS Appl. Mater. Interfaces 2014, 6, 14702-14711.

(53) Monyoncho, E. A.; Ntais, S.; Brazeau, N.; Wu, J.-J.; Sun, C.-L.; Baranova, E. A., Role of the Metal-Oxide Support in the Catalytic Activity of Pd Nanoparticles for Ethanol Electrooxidation in Alkaline Media. ChemElectroChem 2016, 3, 218-227.

(54) Briggs, D.; Seah, M. P., Practical Surface Analysis by Auger and X-Ray Photoelectron Spectroscopy; John Wiley and Sons Ltd: Chichester, 1996, p 674.

(55) Süzer, S.; Voscoboinikov, T.; Hallam, K. R.; Allen, G. C., Electron Spectroscopic Investigation of Sn Coatings on Glasses. Fresenius J. Anal. Chem. 1996, 355, 654-656.

(56) Howard, S. M., Ellingham Diagrams: Standard Gibbs Energies of Formation for Oxides. SD School of Mines and Technology, Rapid City, SD 2006

(57) Shafeev, G. A.; Themlin, J. M.; Bellard, L.; Marine, W.; Cros, A., Enhanced Adherence of Area-Selective Electroless Metal Plating on Insulators. J. Vac. Sci. Technol. A 1996, 14, 319326.

(58) Gao, W.; Jin, R.; Chen, J.; Guan, X.; Zeng, H.; Zhang, F.; Liu, Z.; Guan, N., TitaniaSupported $\mathrm{Pd}-\mathrm{Cu}$ Bimetallic Catalyst for the Reduction of Nitrite Ions in Drinking Water. Catal. Lett. 2003, 91, 25-30.

(59) Lee, H.-B.-R.; Bent, S. F., Microstructure-Dependent Nucleation in Atomic Layer Deposition of Pt on $\mathrm{TiO}_{2}$. Chem. Mater. 2012, 24, 279-286.

(60) Tighineanu, A.; Ruff, T.; Albu, S.; Hahn, R.; Schmuki, P., Conductivity Of $\mathrm{TiO}_{2}$ Nanotubes: Influence of Annealing Time And Temperature. Chem. Phys. Lett. 2010, 494, 260263.

(61) Horkans, J., The Hydrogen Region of The Cyclic Voltammetry of Pd: The Effect of pH and Anion. J. Electroanal. Chem. 1986, 209, 371-376.

(62) Ruiz-Camacho, B.; Santoyo, H. H. R.; Medina-Flores, J. M.; Álvarez-Martínez, O., Platinum Deposited on $\mathrm{TiO}_{2}-\mathrm{C}$ and $\mathrm{SnO}_{2}-\mathrm{C}$ Composites for Methanol Oxidation and Oxygen Reduction. Electrochim. Acta 2014, 120, 344-349.

(63) Chen, Y.; Wang, J.; Meng, X.; Zhong, Y.; Li, R.; Sun, X.; Ye, S.; Knights, S., Pt$\mathrm{SnO}_{2} /$ Nitrogen-Doped CNT Hybrid Catalysts for Proton-Exchange Membrane Fuel Cells (PEMFC): Effects of Crystalline and Amorphous Sno2 By Atomic Layer Deposition. J. Power Sources 2013, 238, 144-149. 
(64) Liang, Z. X.; Zhao, T. S.; Xu, J. B.; Zhu, L. D., Mechanism Study of the Ethanol Oxidation Reaction on Palladium in Alkaline Media. Electrochim. Acta 2009, 54, 2203-2208.

(65) Wieckowski, A.; Savinova, E. R.; Vayenas, C. G., Particle Size, Support and Promotional Effects. In Catalysis and Electrocatalysis at Nanoparticle Surfaces, Marcel Dekker: New York, 2003; pp 613-847.

(66) Mao, H.; Wang, L.; Zhu, P.; Xu, Q.; Li, Q., Carbon-Supported PdSn-SnO ${ }_{2}$ Catalyst for Ethanol Electro-Oxidation in Alkaline Media. Int. J. Hydrogen Energy 2014, 39, 17583-17588.

(67) Takabatake, Y.; Noda,Z.; Lyth, S. M.; Hayashi, A.; Sasaki, K., Cycle Durability of Metal Oxide Supports for PEFC Electrocatalysts. Int. J. Hydrogen Energy 2014, 39, 5074-5082.

(68) Kim, J. H.; Choi, S. M.; Nam, S. H.; Seo, M. H.; Choi, S. H.; Kim, W. B., Influence of Sn Content On PtSn/C Catalysts for Electrooxidation Of C1-C3 Alcohols: Synthesis, Characterization, and Electrocatalytic Activity. Appl. Catal., B 2008, 82, 89-102.

(69) Skriver, H. L.; Rosengaard, N. M., Ab Initio Work Function of Elemental Metals. Phys. Rev. B 1992, 45, 9410-9412.

(70) Chen, Y.-X., et al., Electrochemical Milling and Faceting: Size Reduction and Catalytic Activation of Palladium Nanoparticles. Angew. Chem. Int. Ed. 2012, 51, 8500-8504.

(71) Marichy, C.; Ercolano, G.; Caputo, G.; Willinger, M. G.; Jones, D.; Roziere, J.; Pinna, N.; Cavaliere, S., ALD $\mathrm{SnO}_{2}$ Protective Decoration Enhances the Durability of a Pt Based Electrocatalyst. J. Mater. Chem. A 2016, 4, 969-975.

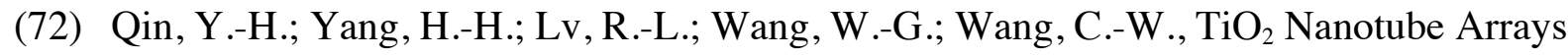
Supported Pd Nanoparticles forr Ethanol Electrooxidation in Alkaline Media. Electrochim. Acta 2013, 106, 372-377.

(73) Rikkinen, E.; Santasalo-Aarnio, A.; Airaksinen, S.; Borghei, M.; Viitanen, V.; Sainio, J.; Kauppinen, E. I.; Kallio, T.; Krause, A. O. I., Atomic Layer Deposition Preparation of Pd Nanoparticles on a Porous Carbon Support for Alcohol Oxidation. J. Phys. Chem. C 2011, 115, 23067-23073.

(74) Monyoncho, E. A.; Steinmann, S. N.; Michel, C.; Baranova, E. A.; Woo, T. K.; Sautet, P., Ethanol Electro-oxidation on Palladium Revisited Using Polarization Modulation Infrared Reflection Absorption Spectroscopy (PM-IRRAS) and Density Functional Theory (DFT): Why Is It Difficult To Break the C-C Bond? ACS Catal. 2016, 6, 4894-4906.

(75) An, H.; Cui, H.; Zhou, D.; Tao, D.; Li, B.; Zhai, J.; Li, Q., Synthesis and Performance of $\mathrm{Pd} / \mathrm{SnO}_{2}-\mathrm{TiO}_{2} / \mathrm{MWCNT}$ Catalysts for Direct Formic Acid Fuel Cell Application. Electrochim. Acta 2013, 92, 176-182. 

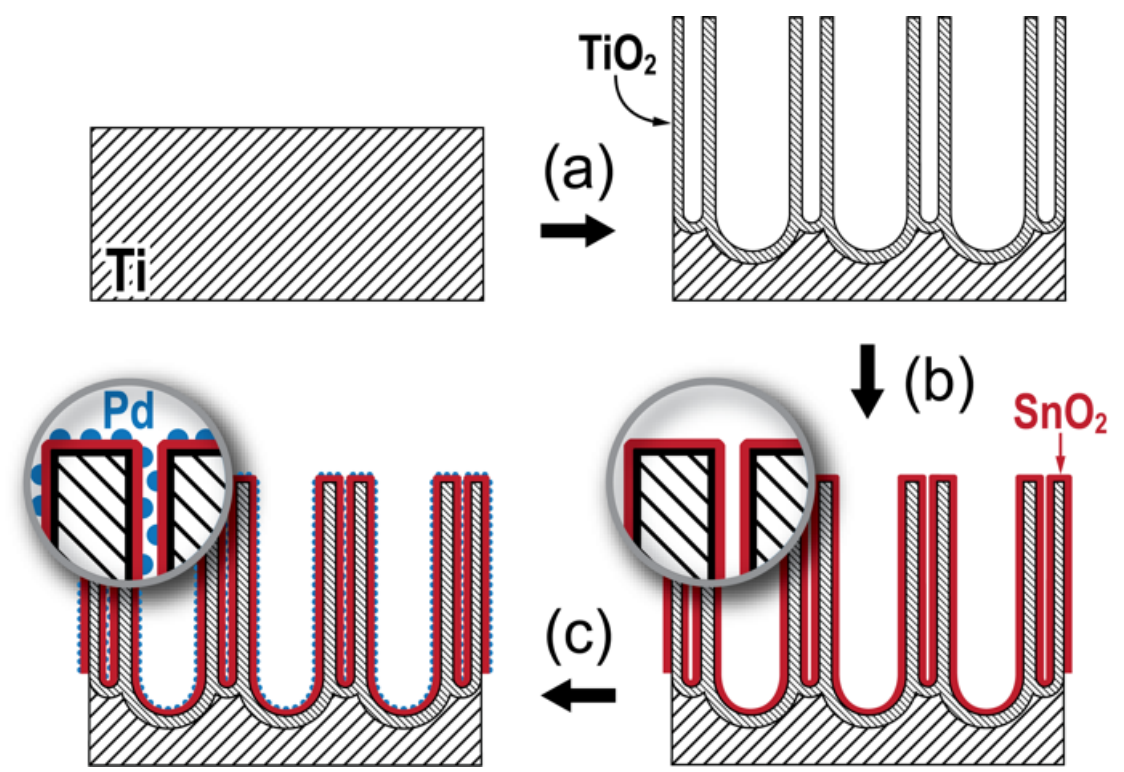

Figure 1: Schematic view of the process. (a) Anodic growth of the $\mathrm{TiO}_{2}$ nanotubes, (b) ALD of $\mathrm{SnO}_{2}$ and (c) ALD of Pd. 

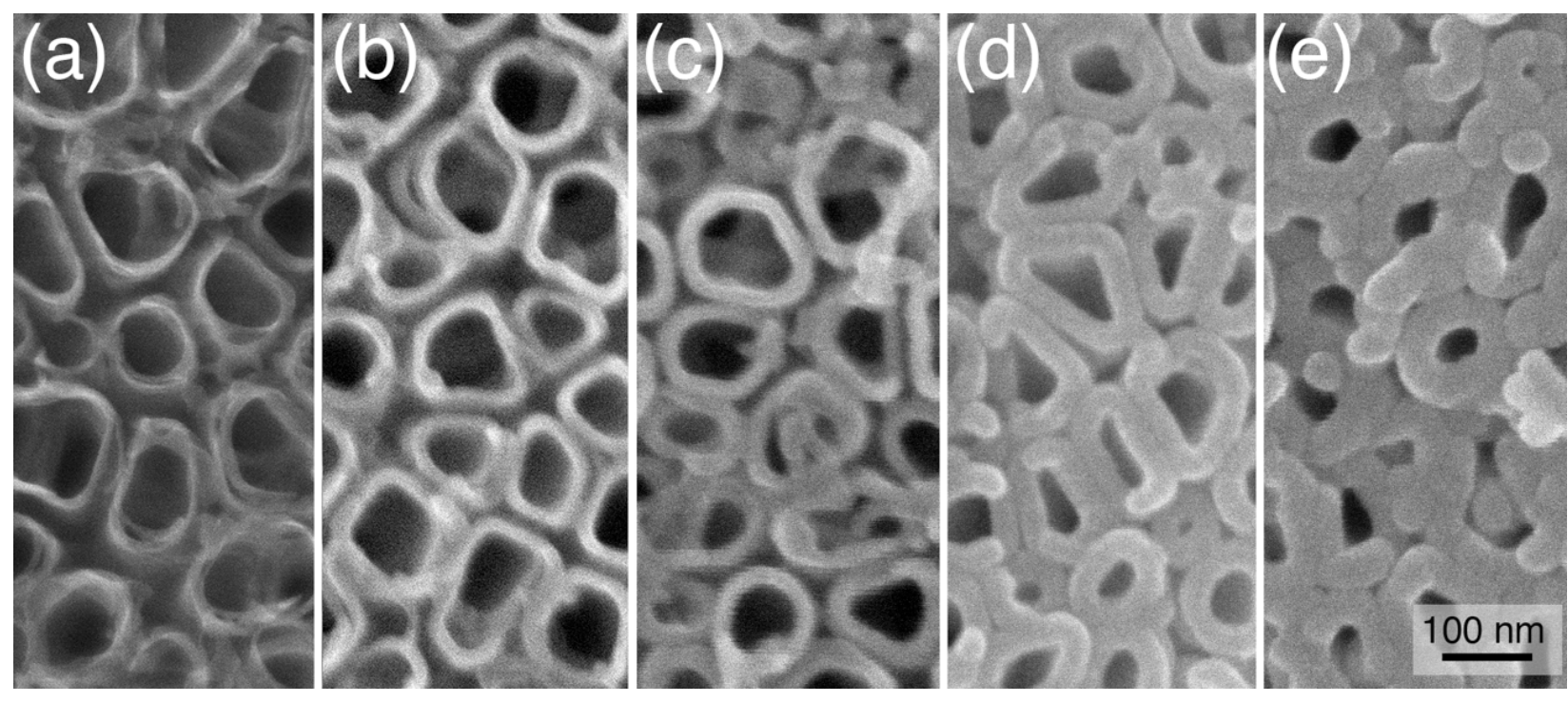

Figure 2: $\mathrm{SEM}$ top views of $\mathrm{TiO}_{2}$ nanotubes covered by a thin $\mathrm{SnO}_{2}$ layer. The number of ALD cycles $\left(N_{\mathrm{SnO}_{2}}\right)$ is increasing from $0(\mathrm{a}), 20$ (b), 50 (c), 100 (d) to 150 cycles (e). 


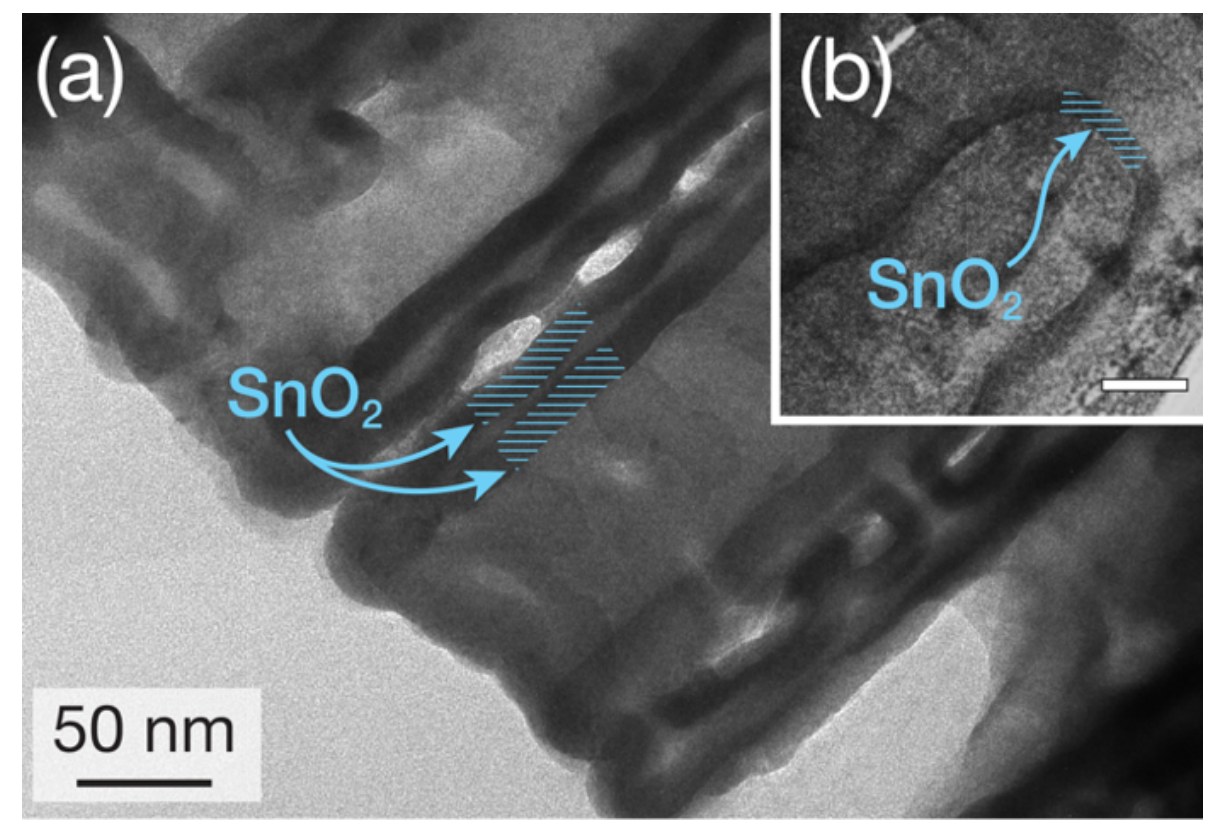

Figure 3: TEM cross sections of the opening (a) and the bottom (b) of TNTs after ALD of $\mathrm{SnO}_{2}$ (a). The scale bar in (b) corresponds to $20 \mathrm{~nm}$. 


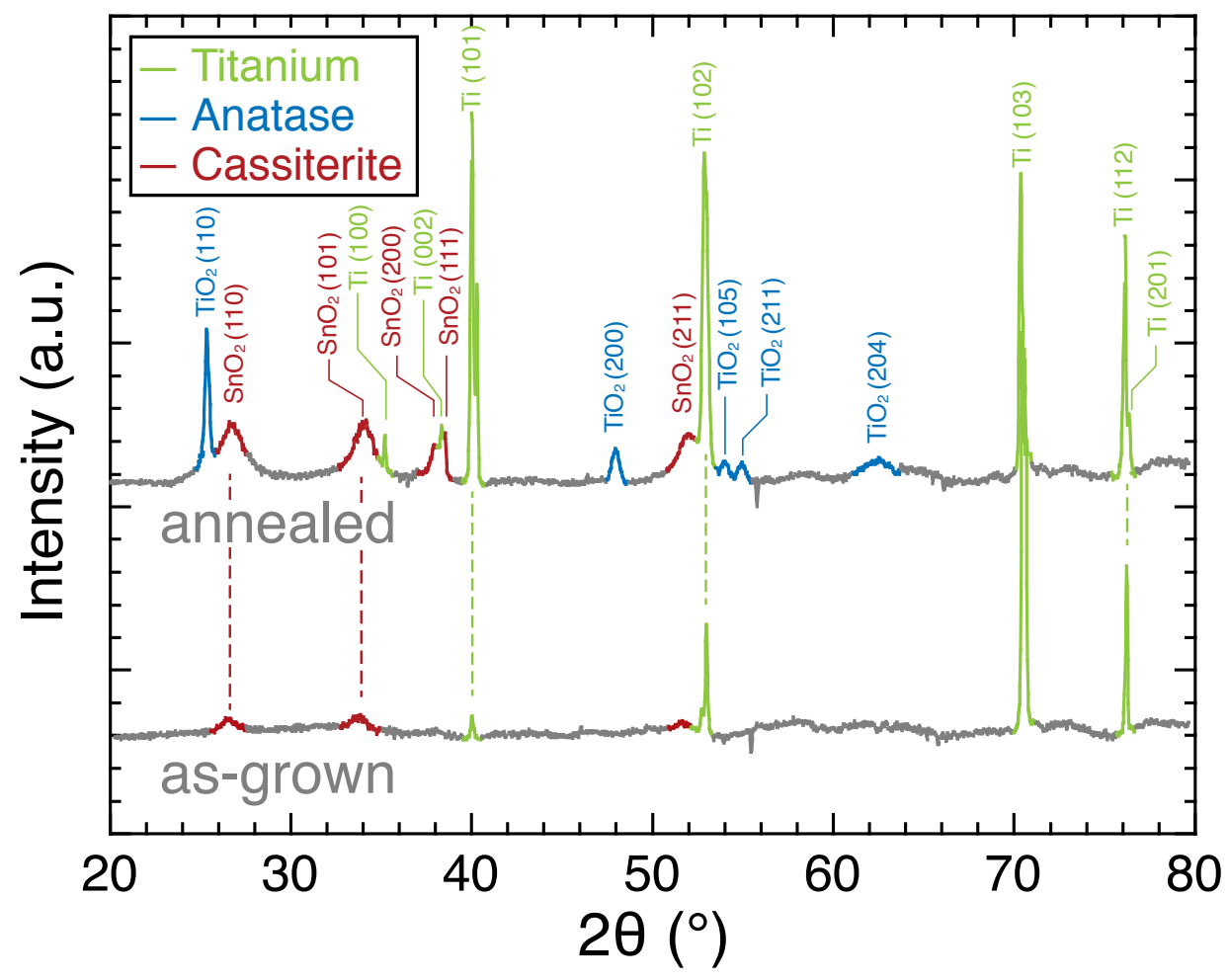

Figure 4: $\mathrm{X}$-ray diffractograms of $\mathrm{SnO}_{2}$-coated TNTs before (bottom) and after (top) annealing at $450^{\circ} \mathrm{C}$ 

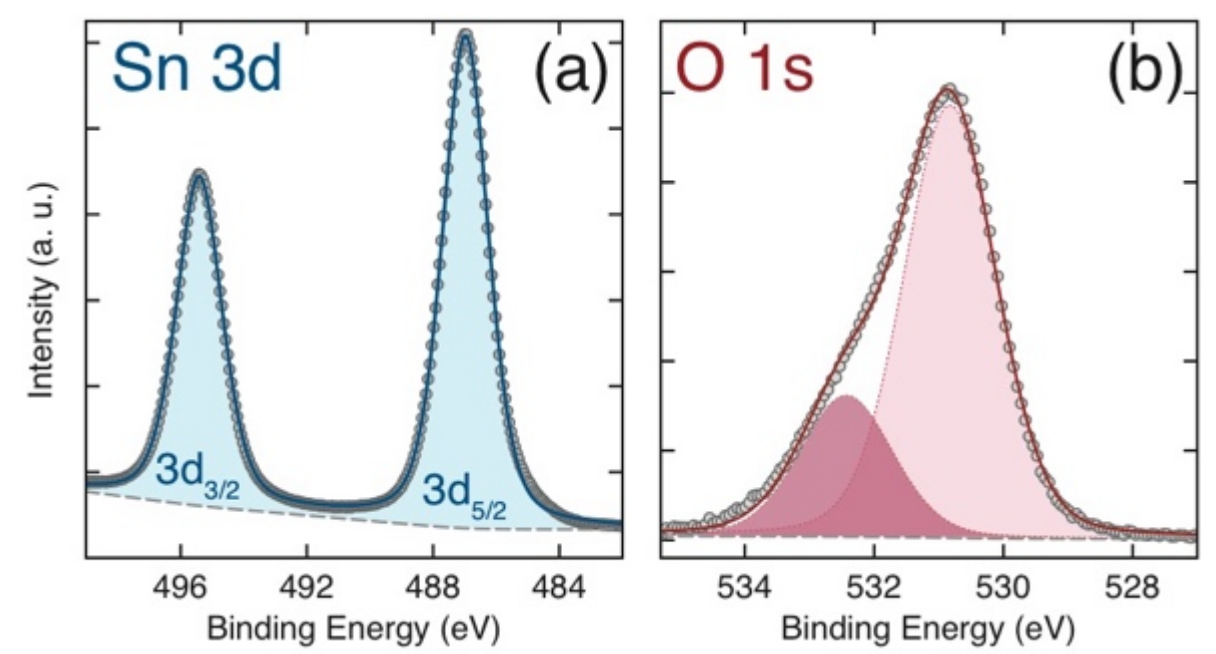

Figure 5: $\mathrm{Sn} 3 \mathrm{~d}$ (a) and $\mathrm{O} 1 \mathrm{~s}(\mathrm{~b}) \mathrm{XPS}$ peaks of $\mathrm{SnO}_{2}$-coated TNTs $\left(N_{\mathrm{SnO}^{2}}=50\right.$ cycles $)$ 


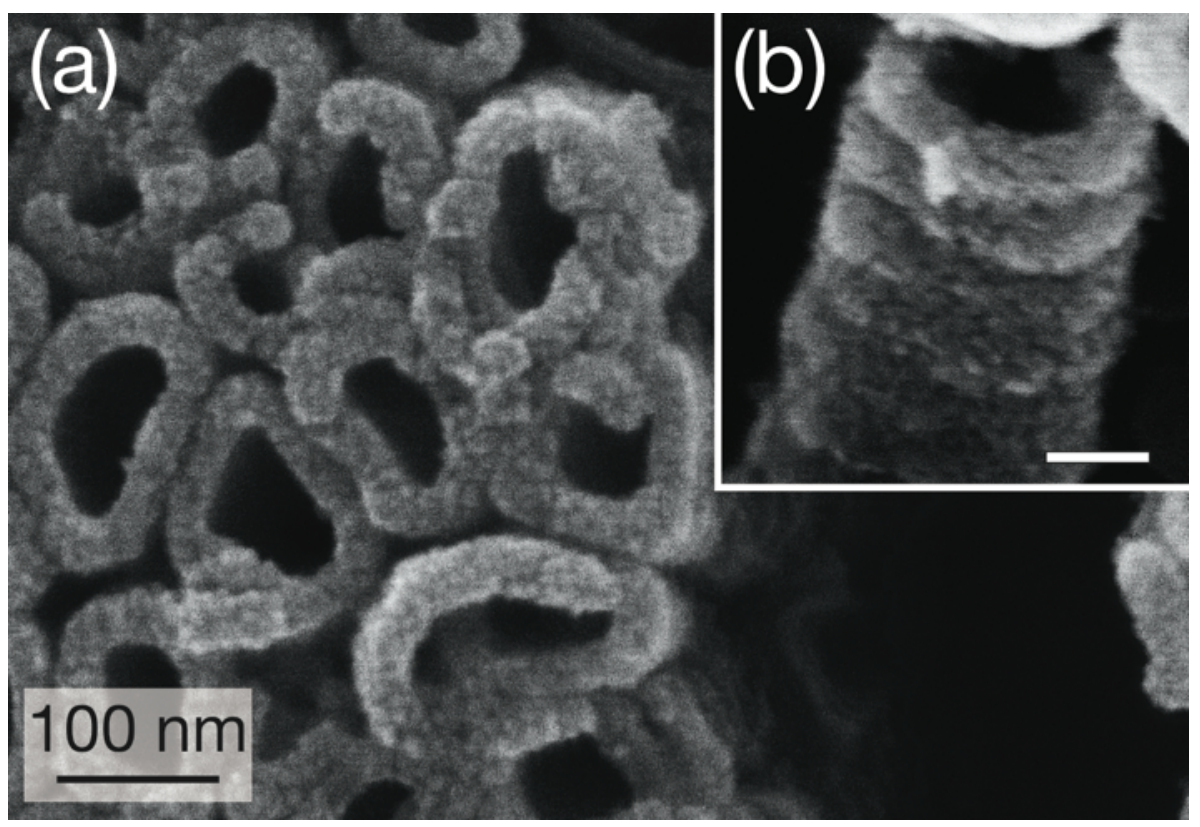

Figure 6: $\mathrm{SEM}$ images of $\mathrm{SnO}_{2} / \mathrm{TNT}$ after ALD of Pd $\left(N_{\mathrm{Pd}}=600\right.$ cycles): (a) top view and (b) side view. The scale bar in (b) corresponds to $50 \mathrm{~nm}$. 

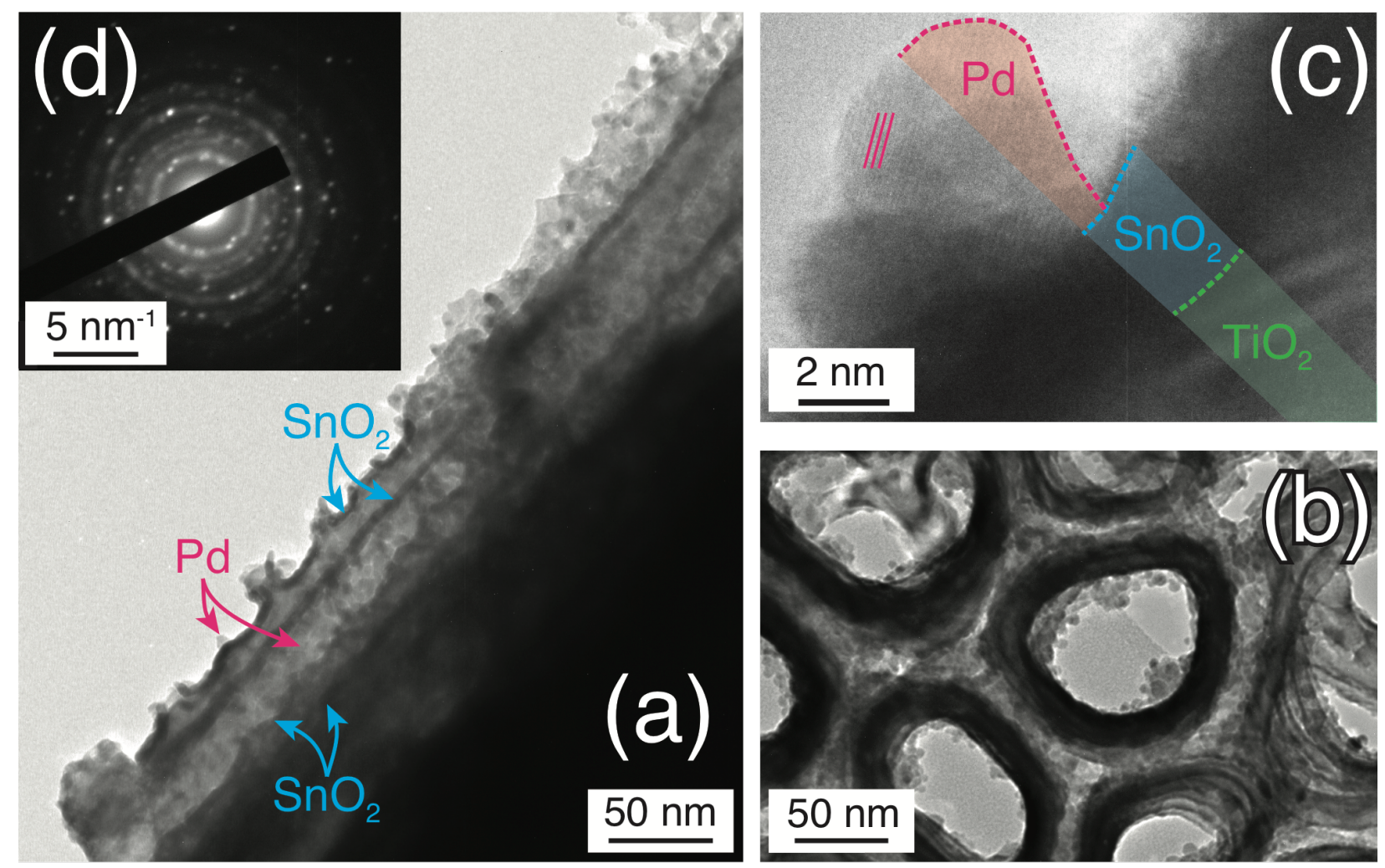

Figure 7: TEM images of $\mathrm{SnO}_{2} /$ TNTs annealed after ALD of $\mathrm{Pd}\left(N_{\mathrm{Pd}}=500\right.$ cycles):

(a) cross section of a single nanotube, (b) top view of several nanotubes, (c) highmagnification of Pd particles on a tube wall and (d) SAED corresponding to the area shown in (b). The various materials are artificially colored in (c) for seek of clarity and the three red lines highlight the Pd crystal rows. 

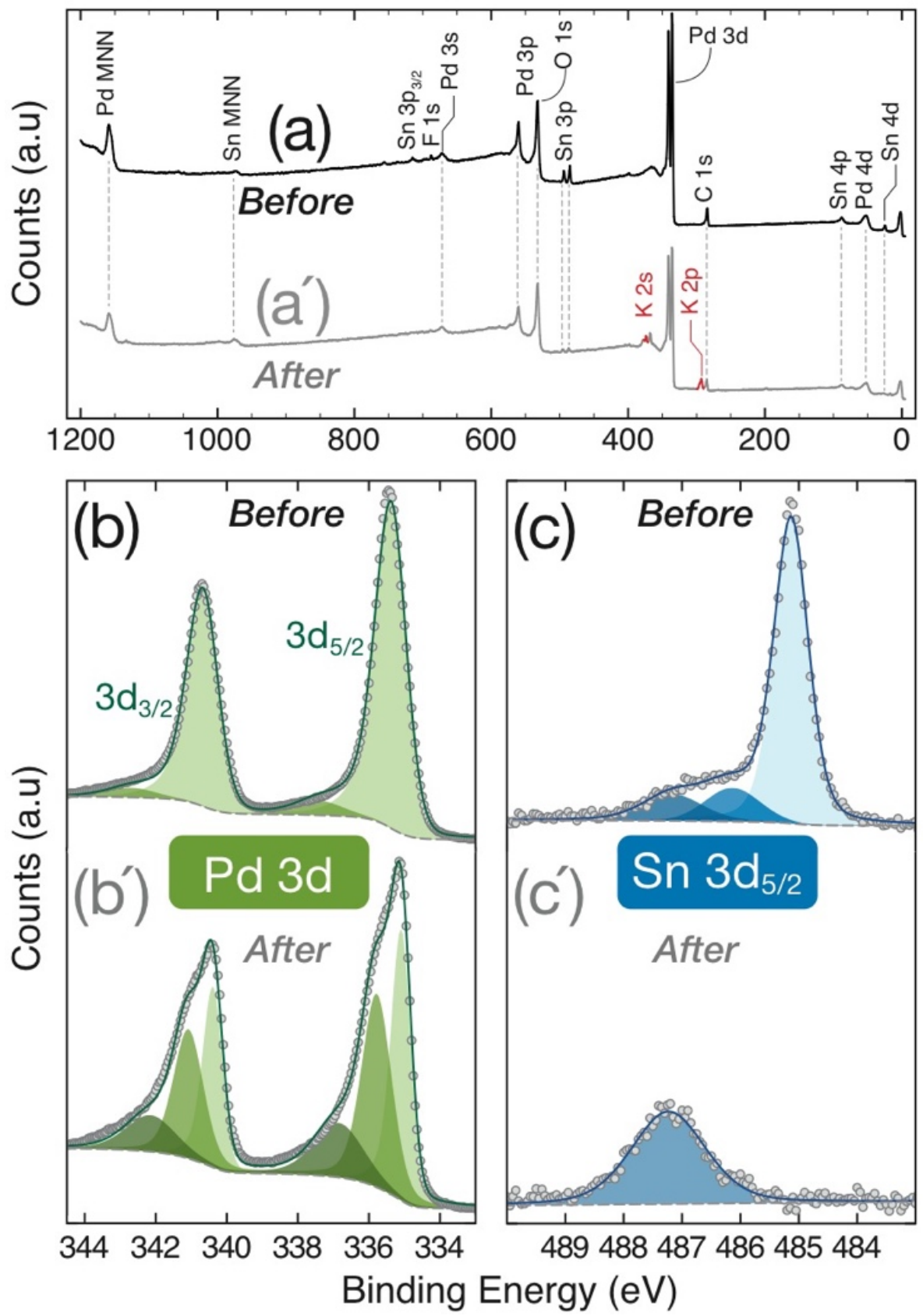

Figure 8: Comparison of the chemical composition of the surface before $(a, b, c)$ and after $\left(\mathrm{a}^{\prime}, \mathrm{b}^{\prime}, \mathrm{c}^{\prime}\right)$ electrochemical investigations performed on annealed $\mathrm{Pd} / \mathrm{SnO}_{2} / \mathrm{TNTs}$.

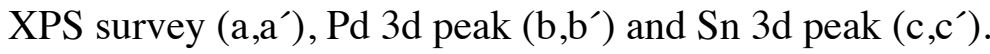




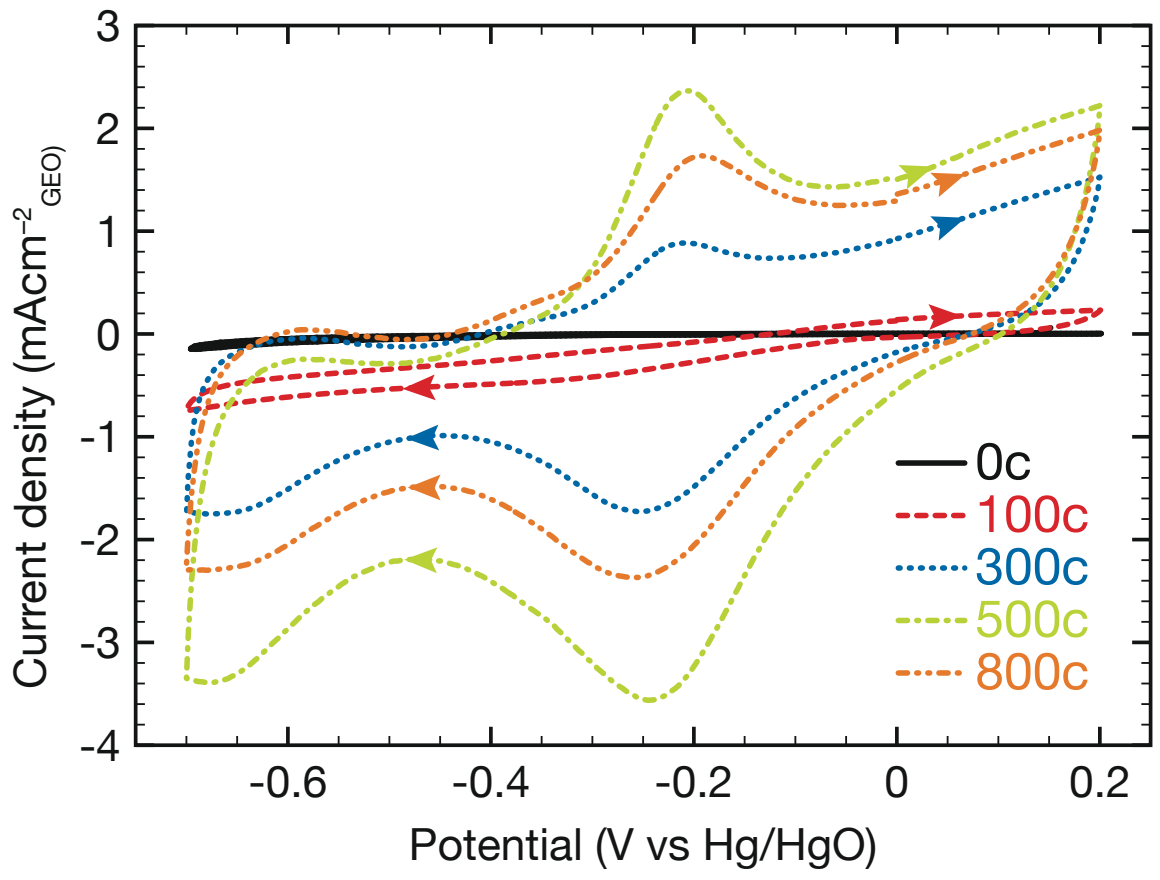

Figure 9: CVs of as-grown $\mathrm{SnO}_{2} / \mathrm{TNT}$ after ALD of Pd for $N_{\mathrm{Pd}}=0,100,300,500$ and 800 cycles. The electrolyte is $1 \mathrm{M} \mathrm{KOH}$ and the scan rate is $25 \mathrm{mV} \mathrm{s}^{-1}$. 


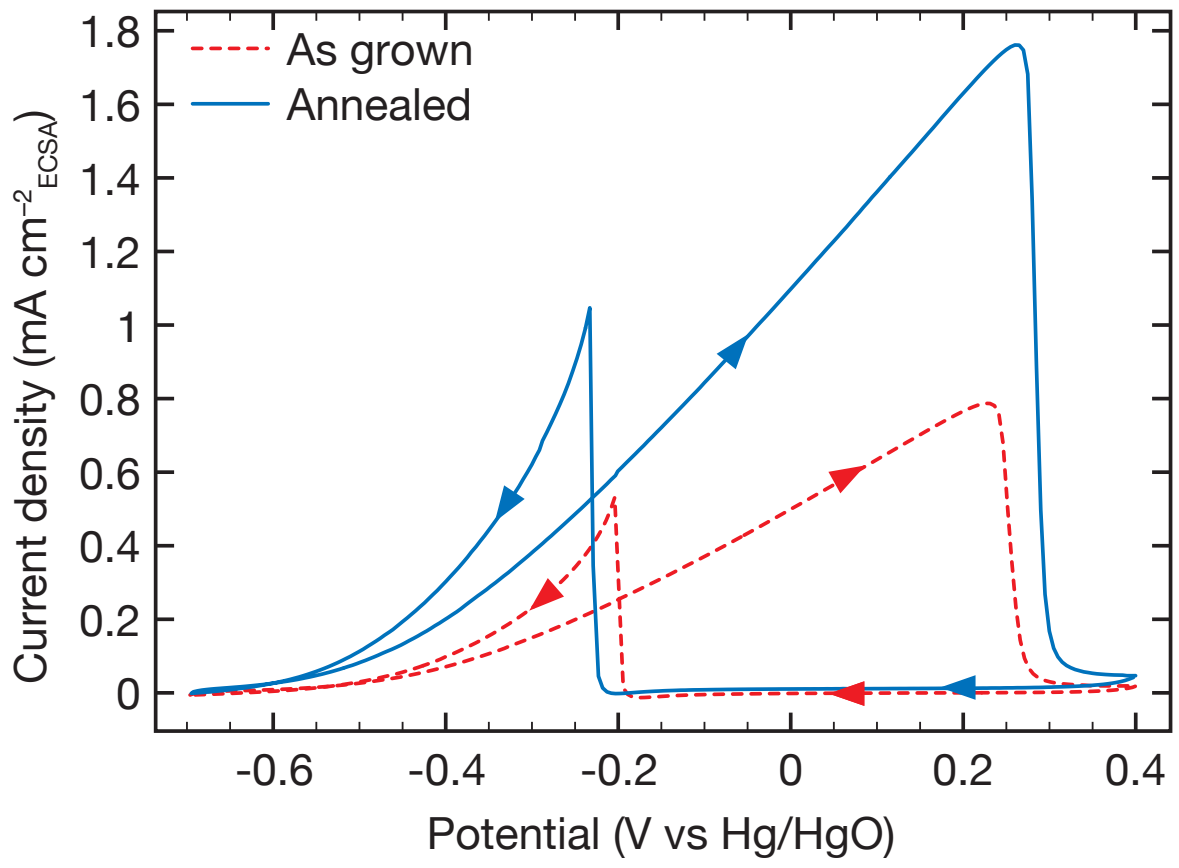

Figure 10: Cyclic voltametry of as-grown (red line) and annealed (blue line) $\mathrm{SnO}_{2} /$ TNTs after $500 \mathrm{Pd}$ cycles. The electrolyte is $1 \mathrm{M} \mathrm{KOH}+1 \mathrm{M} \mathrm{C}_{2} \mathrm{H}_{5} \mathrm{OH}$ and the scan rate is $25 \mathrm{mV} \mathrm{s}^{-1}$. 


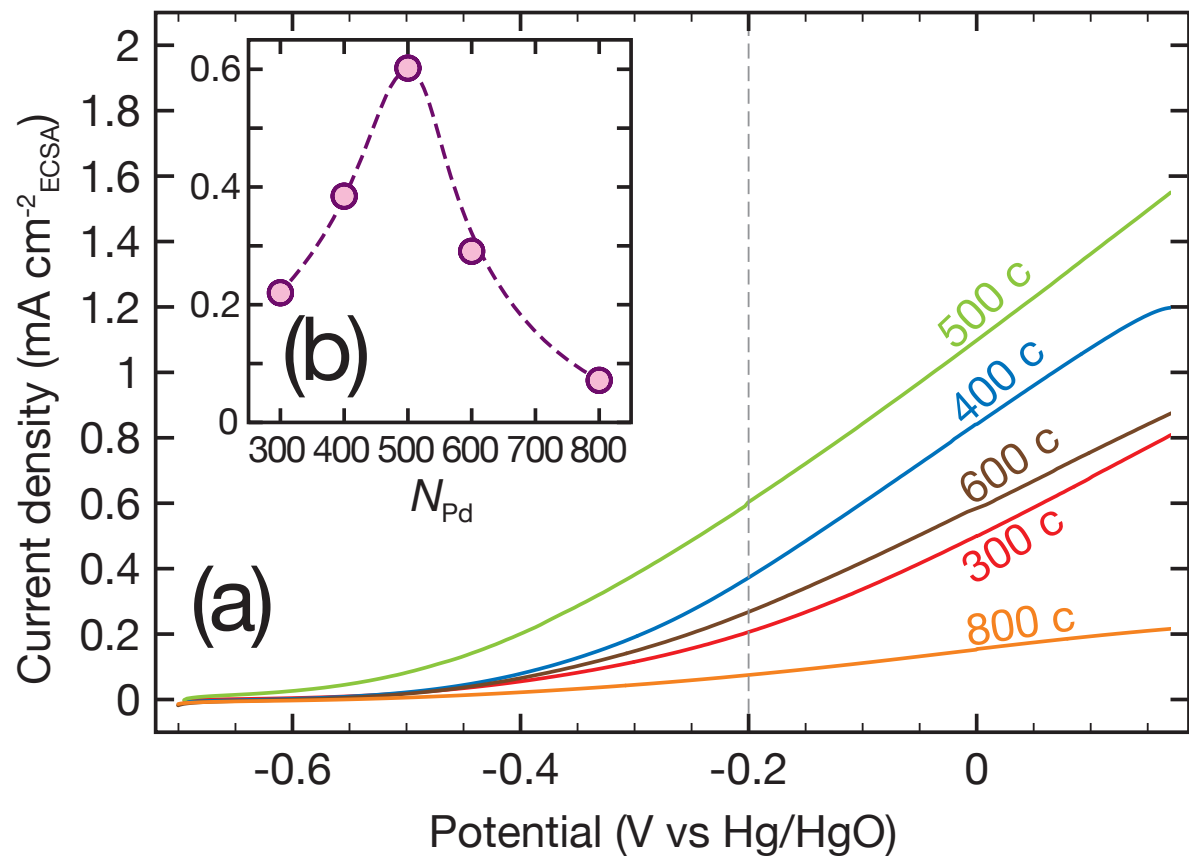

Figure 11: (a) Forward scans and (b) current density measured at $-0.2 \mathrm{~V}$ for annealed $\mathrm{SnO}_{2} /$ TNTs after ALD of Pd for $N_{\mathrm{Pd}}=300,400,500,600$ and 800 cycles. The electrolyte is $1 \mathrm{M} \mathrm{KOH}+1 \mathrm{M} \mathrm{C}_{2} \mathrm{H}_{5} \mathrm{OH}$ and the scan rate is $25 \mathrm{mV} \mathrm{s}^{-1}$. 


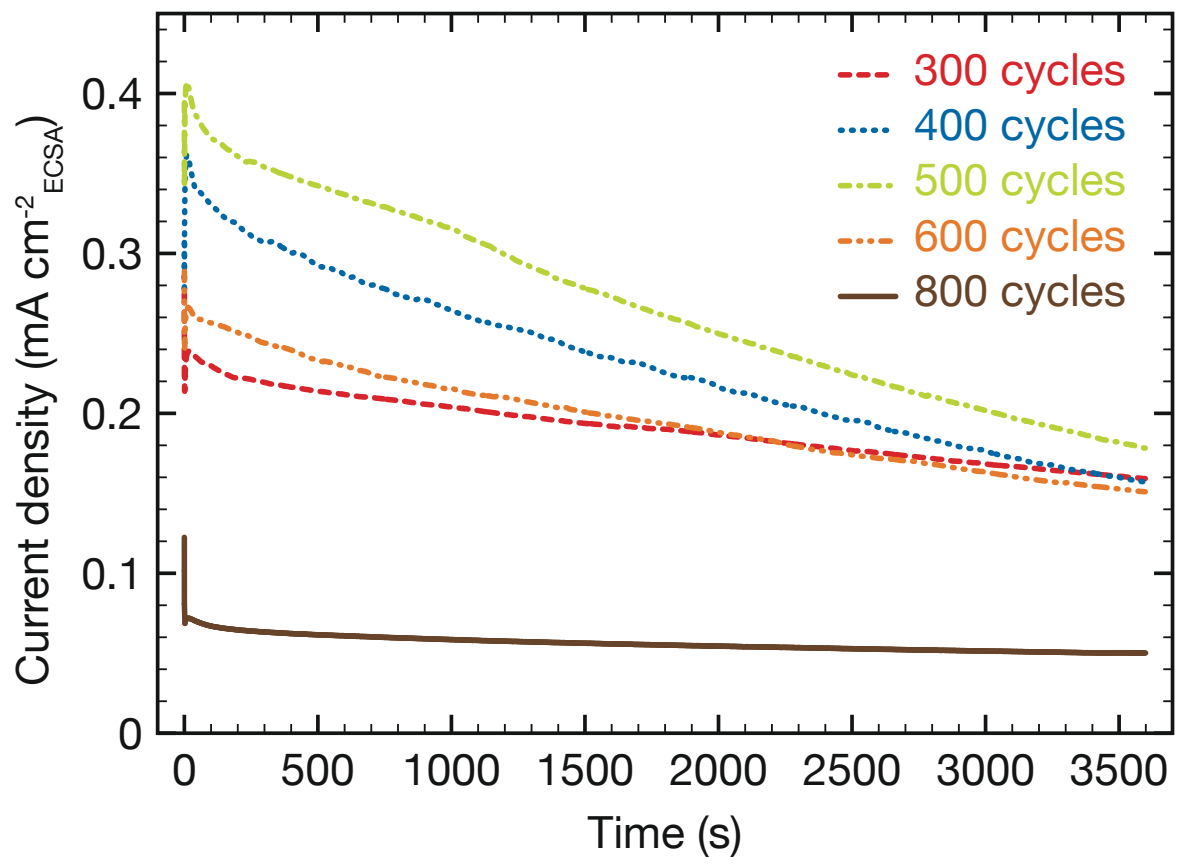

Figure 12: Chronoamperograms of annealed $\mathrm{Pd} / \mathrm{SnO}_{2} / \mathrm{TNTs}$ catalysts with different amount of deposited $\mathrm{Pd}$, as indicated in the figure, at $-0.2 \mathrm{~V}$ in $1 \mathrm{M} \mathrm{KOH}+1 \mathrm{M}$ $\mathrm{C}_{2} \mathrm{H}_{5} \mathrm{OH}$. 


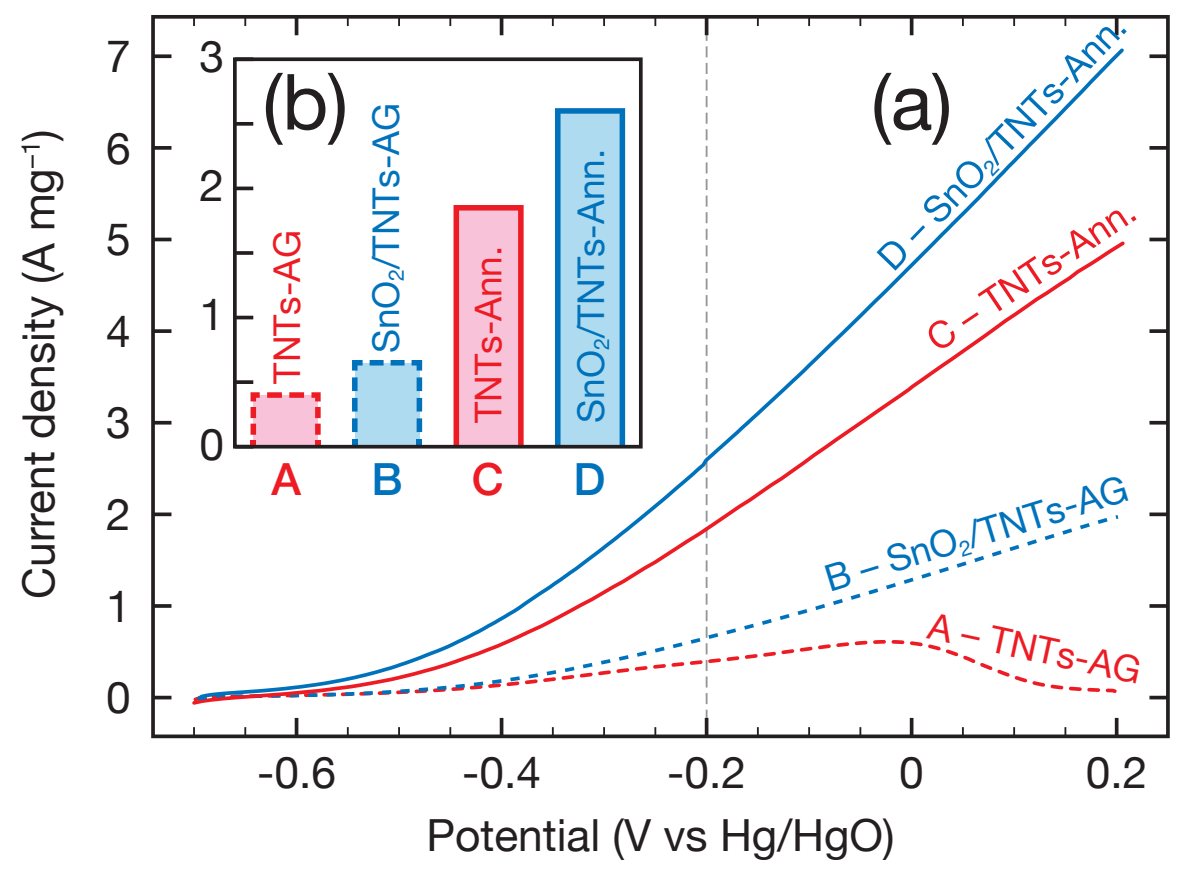

Figure 13: (a) Linear sweep voltammetry and (b) current density measured at $-0.2 \mathrm{~V}$ for 500 cycles of Pd on as-grown TNTs, annealed TNTs, as-grown $\mathrm{SnO}_{2} / \mathrm{TNTs}$ and annealed $\mathrm{SnO}_{2} /$ TNTs. The electrolyte is $1 \mathrm{M} \mathrm{KOH}+1 \mathrm{M} \mathrm{C}_{2} \mathrm{H}_{5} \mathrm{OH}$ and the scan rate is $25 \mathrm{mV} \mathrm{s}^{-1}$. 


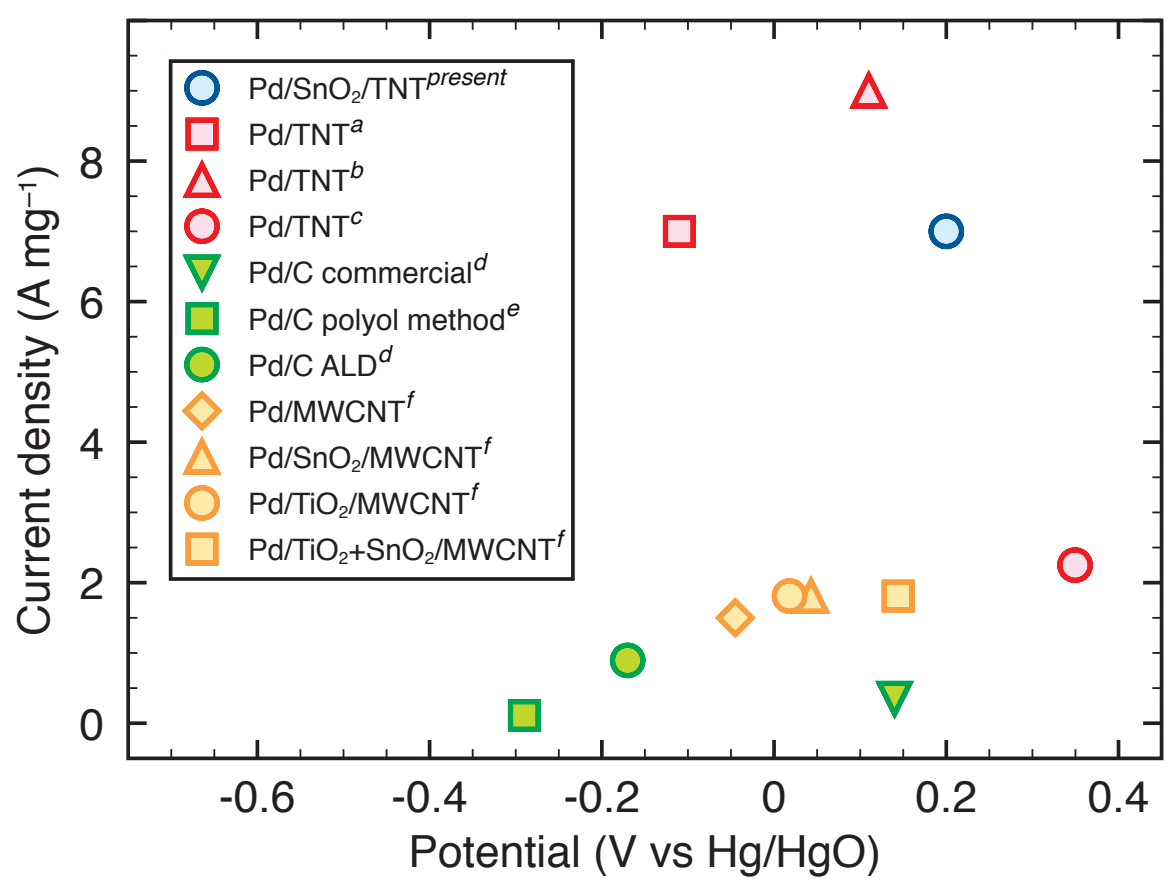

Figure 14: Comparison of the forward ethanol electrooxidation peak current and potential on Pd catalysts deposited on various types of substrates. The CVs are performed in alkaline media containing ethanol with a scanning rate ranging from 5 to $50 \mathrm{mV} \mathrm{s}^{-1}$ (see detailed information in Figure S7). Pd/TNT ${ }^{a},{ }^{72} \mathrm{Pd} / \mathrm{TNT}^{b},{ }^{70} \mathrm{Pd} / \mathrm{TNT}^{c},{ }^{16}$ $\mathrm{Pd} / \mathrm{C} \quad$ commercial $^{d,}{ }^{73} \quad \mathrm{Pd} / \mathrm{C} \quad \mathrm{ALD}^{d}{ }^{d 3} \quad \mathrm{Pd} / \mathrm{C}$ polyol methode $^{74}{ }^{74} \mathrm{Pd} / \mathrm{MWCNT}^{f}$, $\mathrm{Pd} / \mathrm{SnO}_{2} / \mathrm{MWCNT}^{f}, \mathrm{Pd} / \mathrm{TiO}_{2} / \mathrm{MWCNT}^{f}, \mathrm{Pd} / \mathrm{TiO}_{2}+\mathrm{SnO}_{2} / \mathrm{MWCNT}^{f} .^{75}$ 


\section{TOC Graphic}

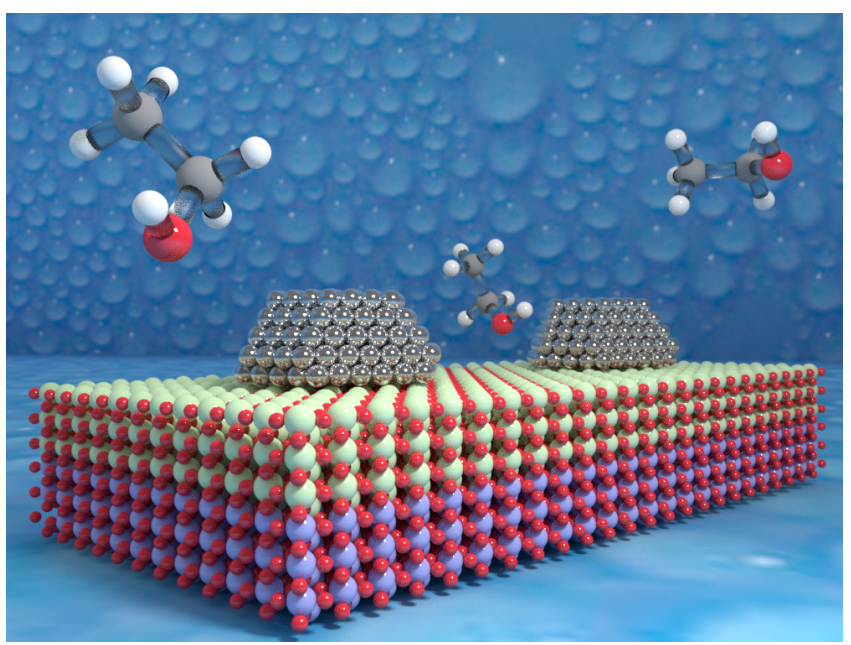

